Int. J. Dev. Biol. 56: 637-652 (2012)

doi: $10.1387 / \mathrm{ijdb} .123523 \mathrm{pb}$

\title{
How to use Hydra as a model system to teach biology in the classroom
}

\author{
PATRICIA BOSSERT ${ }^{1}$ and BRIGITTE GALLIOT ${ }^{*, 2}$ \\ ${ }^{1}$ University of Stony Brook, New York, USA and \\ ${ }^{2}$ Department of Genetics and Evolution, University of Geneva, Switzerland
}

\begin{abstract}
As scientists it is our duty to fight against obscurantism and loss of rational thinking if we want politicians and citizens to freely make the most intelligent choices for the future generations. With that aim, the scientific education and training of young students is an obvious and urgent necessity. We claim here that $H y d r a$ provides a highly versatile but cheap model organism to study biology at any age. Teachers of biology have the unenviable task of motivating young people, who with many other motivations that are quite valid, nevertheless must be guided along a path congruent with a 'syllabus' or a 'curriculum!. The biology of Hydra spans the history of biology as an experimental science from Trembley's first manipulations designed to determine if the green polyp he found was plant or animal to the dissection of the molecular cascades underpinning, regeneration, wound healing, stemness, aging and cancer. It is described here in terms designed to elicit its wider use in classrooms. Simple lessons are outlined in sufficient detail for beginners to enter the world of 'Hydra biology'. Protocols start with the simplest observations to experiments that have been pretested with students in the USA and in Europe. The lessons are practical and can be used to bring 'life', but also rational thinking into the study of life for the teachers of students from elementary school through early university.
\end{abstract}

KEY WORDS: ecology, evolution and developmental biology education, science policy, authentic assessment, inquiry-based learning, student portfolio

\section{How the authors met the Hydra model system}

In the USA, Patricia Bossert taught Biology on Long Island for 35 years, making Hydra her accomplice for many of those years. Initially trained as a classroom teacher, she decided to go back to academic studies after 15 years of teaching and, with the support of her family (husband, mother and two young sons), she performed a $\mathrm{PhD}$ in Ecology and Evolution in the laboratory of Lawrence B. Slobodkin at Stony Brook University. During this period she gained a deeper appreciation of the amazing potential of Hydrato address ecological and evolutionary issues experimentally (Bossert and Dunn, 1986; Slobodkin and Bossert, 1991) as well as its outstanding value for stimulating the curiosity of even the youngest students while also providing a challenging model for older students to perform authentic investigations. Thanks to her original approach that combined ecology and evolution with molecular strategies, several of them obtained prizes in national and international scientific competitions. This led her to be recruited by Stony Brook University as an expert for mentoring teachers to do research using Hydra; focusing on students from families of lower socio-economic status. In Europe, Brigitte Galliot performed medical studies in Paris and a PhD in Life Sciences in the laboratory of Pierre Chambon in Strasbourg (France). Thereafter she was introduced to the Hydra model system as a post-doc in the laboratory of Chica Schaller in Heidelberg (Germany). In 1993 she moved with her husband and four children to Geneva where she had the chance to establish her own lab at the Faculty of Sciences. Since then her lab follows a line of research focusing on the molecular and cellular basis of regeneration and neurogenesis using Hydra as a model system. In parallel her lab provides Hydra and advice to teachers and students of schools, colleges and universities (http://genev.unige.ch/ en/users/Brigitte-Galliot/unit/orders/new) and regularly participates in public events for all ages as the "Nuit de la Science". Both met "in silico" in 1996 when PB contacted BG to get some information on the transcriptional regulation of head regeneration. Since then

Abbreviations used in this paper: DAPI, 4,6-diamidino-2-phenylindole (fluorescent die that binds A-T rich regions in DNA); HHI, Hydra health index; HM, Hydra medium; hpa, hours post-amputation; i-cells, interstitial cells; RT, room temperature; UV, ultraviolet light.

*Address correspondence to: Brigitte Galliot. Department of Genetics and Evolution, University of Geneva, Switzerland. e-mail: brigitte.galliot@ unige.ch

Final, author-corrected PDF published online: 5 June 2012

ISSN: Online 1696-3547, Print 0214-6282

(C) 2012 UBC Press

Printed in Spain 
they kept interacting mostly via email until PB decided to spend a six months sabbatical stay in Galliot's lab in 2011. This article was discussed, assayed and written during that period.

\section{Hydra pedagogy and the origin of experimental biology}

The ability to engage the mind of a student and propel it toward self-directed inquiry is perhaps the cornerstone of effective pedagogy. We claim no master plan, no all-inclusive secret for igniting the intellect of the young (and often restless) mind. Indeed we are convinced that for those of us who teach biology, we should do as Abraham Trembley did: Bring Hydra into our classroom/laboratory (see in this issue the review by Marc Ratcliff, Fig. 6, Ratcliff, 2012). Born in Geneva, Switzerland (1710), Trembley was employed as a tutor for the children of various noblemen in Holland beginning in 1733. A sample of pond water he collected on the estate of Count Bentinck contained a host of plants and animals and also a green polyp he had not seen before. Careful observation finally convinced him that it was an animal and so he set the jar containing the pond water aside on a windowsill. Over a month passed before he noticed that the polyps had moved to the side of the jar closest to the window. This chance observation forced him to reexamine his conclusion that they were animals. Knowing that plants could regenerate but that most animals could not, he records the following in his diary (translated by Lenhoff and Lenhoff): "The first operation I performed on the polyps was to cut them transversely. I place it with a little water in the hollow of my left hand. When I have it, as I want it, I delicately pass one blade of the scissors, which I hold in my right hand, under the part of the polyp's body where it is to be severed. Then I close the scissors." (Trembley, 1744; Lenhoff and Lenhoff, 1986). "Then I close the scissors" and so with this simple maneuver begins biology as an experimental science.

Today studies using Hydra span biology from ecology and evolution to the molecular cascades underpinning wound healing, development and regeneration (see chapters in this issue). Here we offer practical advice for obtaining and maintaining Hydra and some simple experiments you can do in the classroom. The experiments described here begin with the simplest experience that can be accomplished in one day with even young students to longer-term investigations with older students that could take weeks, months or longer. What can you and your students learn by doing this? Is it worth the effort? The answers to these questions are like beauty, of course, 'in the eye of the beholder'.

\section{Hydra in its natural environment}

\section{Key concepts: anatomy, taxonomy, biogeography}

Hydra are small freshwater cnidarian polyps that under controlled feeding and temperature reach a steady state size $(5-20 \mathrm{~mm})$ characteristic of species and strain (Hecker and Slobodkin, 1976). The body is tubular consisting of two layers of epithelio-muscular cells connected by a gelatinous extracellular matrix (the mesoglea) interspersed with collagen fibers having great elasticity. The outer epithelium (ectoderm) is made of myoepithelial cells that form an 'epidermis' (i.e. a functional barrier to the environment); the inner epithelium (endoderm) contains myoepithelial cells that act as digestive cells, phagocytosing nutrients with the help of the gland cells that secrete proteases (Lentz, 1966). In green Hydra (that contain intracellular Chlorella-like algae) specific Hydra lysins belonging to a novel family of Pore-Forming Proteins are secreted into the gastrovascular cavity probably aiding in the digestion of prey (Sher et al., 2005).

Both epithelial layers contain interstitial cell derivatives; indeed interstitial stem cells (that are exclusively found in the ectoderm) differentiate into nerve cells and nematocytes (mechano-sensory cells characteristic of Cnidaria), but also into gland cells that migrate towards the endoderm as well as germ cells when the animal follow the sexual cycle (Bode, 1996b). Nerve cells are found in both layers. All three cells lineages, ectodermal myoepithelial, endodermal myoepithelial and interstitial cells, have the properties of stem cells (reviewed in (Bode, 1996b; Steele, 2002; Galliot et al., 2006; Bosch et al., 2010). Whereas the nervous system consists of a simple net of neurons along the body column, a much higher neuronal density is observed at both extremities; moreover a nerve ring was clearly identified in some species just above the tentacles. This organization likely supports a surprisingly complex behavior of Hydra and in fact the 'simple' net shows higher levels of organiza-
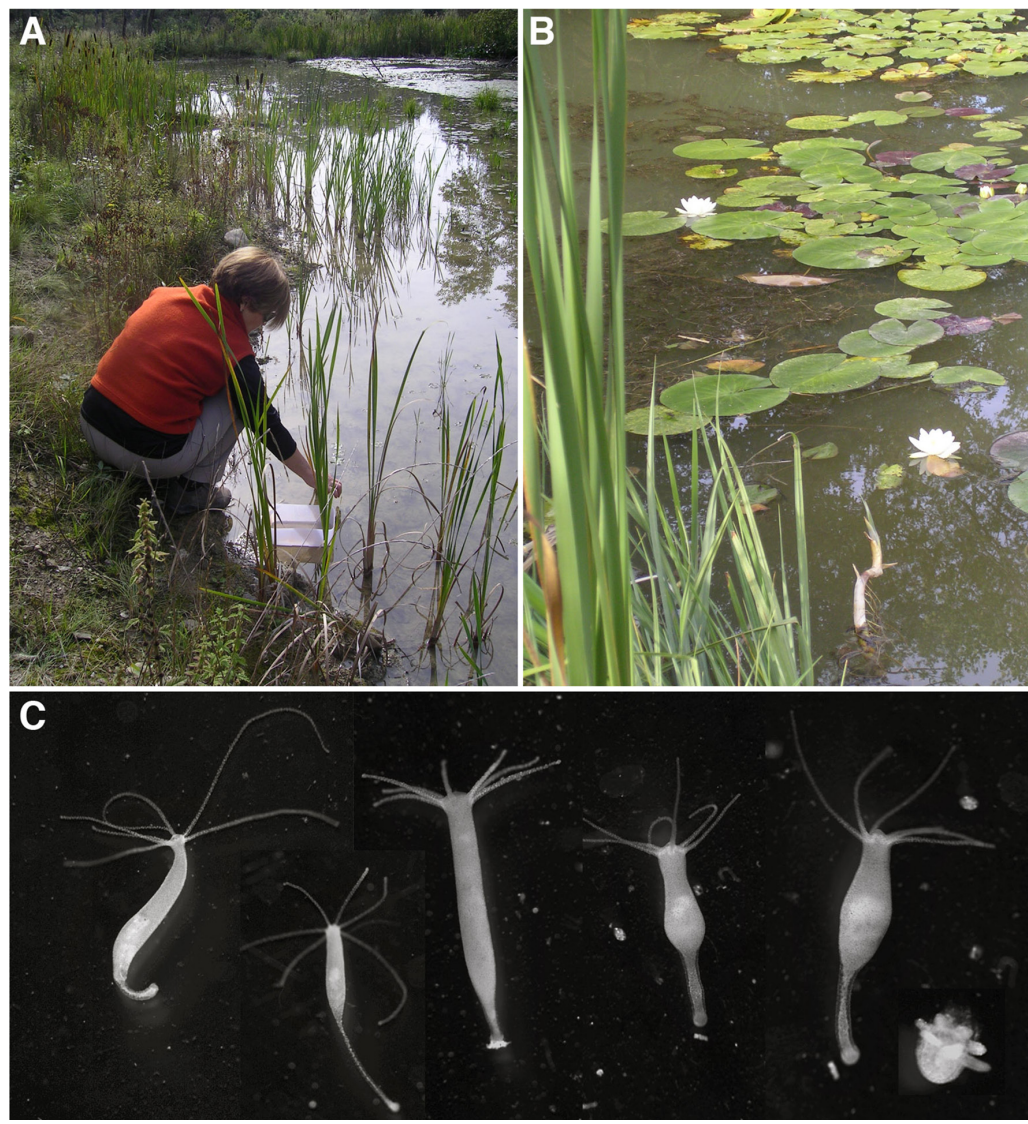

Fig. 1. Hydra fishing in the Canton of Geneva, Switzerland. (A,B) Patricia Bossert collecting wooden sticks and floating plants (Lily pads) on which she found Hydra polyps attached. (C) Hydra oligactis collected in the pond shown above. Note that most polyps have just eaten some Daphnia (freshwater crustacean) and started budding after a few days in the lab. The small Hydra on the right did not survive the transplantation to the lab. 
tion that may vary between species. One stereotypical behavior is characterized by alternating body shortening and elongation coordinated by the interaction of two neuromuscular pacemaker groups at opposite poles of the animal (Passano and McCullough, 1964). The only opening to the sac-like digestive cavity is at the apex of an elevated cone (the hypostome) from which a ring of tentacles emerges surrounding the mouth.

The tentacles are studded with a battery of complex multi-cellular structures (nematocytes + battery cell) that either paralyze or ensnare small prey (Anderson and Bouchard, 2009; Ozbek et al., 2009). The anatomy of the nematocysts are useful in classification of Hydrainto four main groups vulgaris, oligactis, braueriand viridissima (Schulze, 1917; Semal-van Gansen, 1954; Campbell, 1987b) that are also recognizable by other morphological characteristics (Khalturin et al., 2008; Slobodkin and Bossert, 2009). Reproduction is by asexual budding (which dominates when food is plentiful) and/ or by gametes. The fertilized egg develops into an embryo that may enter a resting stage surrounded by a chitinous covering (thecae), the morphology of which is also useful in classification.

Recent phylogenetic and biogeographical studies of Hydra species using three genetic markers in 101 strains collected from six continents confirmed the four morphologically distinct groups of Hydra and clarified species relationships within them (Kawaida et al., 2010; Martinez et al., 2010). Commonly collected strains are brown (vulgaris or oligactis) and green (viridissima). The latter are symbiotic with intracellular Chlorella-like algae found only in the endoderm. Curiously, the smallest brown Hydra is larger than the largest green Hydra suggesting a developmental constraint on the evolution of this symbiosis (Bossert and Dunn, 1986; Bossert, 1987). These two groups are found on all continents (except Antarctica), whereas Hydra of the other two groups (braueri and oligactis) are restricted to the Northern Hemisphere. Hydra is also found on islands that were once connected to continents such as Japan and Greenland (Schulze, 1927). Their presence on oceanic islands such as Hawaii and Tahiti is attributed to human introduction (Mumford, 1940). It is suggested that Hydra did not disperse across oceans, but rather over the landmass of Pangea before it broke up into continents (Campbell, 1987a).

As noted, $H$. oligactis (unlike $H$. vulgaris) is confined to the Northern Hemisphere and it is considered a coldwater species. Interestingly, $H$. oligactis shows little tolerance for thermal stress (Bosch et al., 1988) and, unlike $H$. vulgaris, does not produce detectable levels of heat shock protein HSP70 in response to thermal stresses or other stresses that would be expected to trigger a heat shock response (Brennecke et al., 1998). This lack of inducible HSP may account for its absence from warmer waters.

\section{The student corner: collecting Hydra in the wild}

Hydracan be found in any reasonably unpolluted body of freshwater in any season (Fig. 1). If sticks, leaves or submerged vegetation are collected and placed overnight in a glass or enamel pan, and the pan is carefully examined under a low power stereomicroscope, Hydra is usually found. Hydra is extremely sensitive to detergent and heavy metals (e.g. even tap water is toxic) so new Pyrex dishes are recommended to receive the water collected. The Hydrapolyps are rarely visible immediately. As the water becomes stationery careful observation with a stereoscope or magnifying glass will usually reveal the extended polyps the next day.

Abundance will depend on the seasonal distribution of zooplank- ton and may vary among streams, ponds and lakes. Laboratory cultures of Hydra float when hungry and attach again after they have been fed (Lomnicki and Slobodkin, 1966), therefore the best place to look for them is often at the downstream end of a lake or the pools in the streams immediately below the lake. Hydra can also become a significant planktonic predator (Griffing, 1965; Elliott et al., 1997) but these populations are not as easy to collect in open water because these small soft-bodied Cnidaria do not tolerate plankton tows very well.

\section{Maintaining Hydra culture in the classroom}

\section{Key concepts: healthy Hydra are essential to perform mean- ingful experiments}

The decision to maintain Hydra longer than 8-10 days will depend on the time and resources available as well as how the Hydra are to be used. Sick Hydra do not behave normally. The simplest demonstration of predator/prey interaction won't work if the Hydra won't eat! Therefore, a fundamental question in a Hydra lab is always "Are the Hydra happy?" Recognizing levels of "happiness' need not be entirely subjective. The 'Hydra Health Index' (HHI) developed by Johnson and Gabel $(1982,1983)$ is suitable for most teaching laboratory experiments (Fig. 2). Clearly the more sophisticated the experiment, the more controlled all parameters of care and strain selection must be. For simple and short term experiments (lasting not more that 10 days) reasonable Hydra health can be expected if the animals are obtained from a commercial source or from a university laboratory. Alternatively Hydra cultures can be maintained for many months in the typical science classroom. The benefit of maintaining Hydra cultures for the longterm is that it provides the opportunity for students to engage in an authentic research experience. The cost of long term culturing is time and patient attention to detail; the benefit is that it does not shield the student from the reality of working with a live organism that, while simple in its needs will wreak havoc with experiments, if those needs are not met. Certainly, a very basic lesson for any potential biologist!

Hydra should be fed with Artemia nauplii immediately after they hatch (Fig. 3). High quality Artemia eggs will hatch in 24 hours at $30^{\circ} \mathrm{C}$ in the appropriate salt solution. The eggs should be stored tightly sealed at $4^{\circ} \mathrm{C}$. The Artemia (or brine shrimp) can be hatched in a variety of ways but the key issue is that they are no more than 24 hours old when fed to Hydra. Older nauplii will become contaminated with fungi and bacteria that will eventually compromise Hydra health. Also freshly hatched brine shrimp are small and this is important especially for green Hydra that are also small and often able to consume only one nauplius per meal. Brine shrimp that are not eaten will die and a sub culture of fungus and bacteria will inevitably coat the Hydra culture dish. Hydra will also egest the remains of Artemia several hours after eating. This debris is also highly detrimental to long-term Hydra health. Therefore, a system of feeding and cleaning dishes needs to be established if the animals are going to be kept for more than 10 days.

\section{The teacher corner: maintaining Hydra in the classroom}

A variety of culture methods from small to massive populations are described in (Lenhoff, 1983) but the minimum requirements for culturing Hydra are 1) access to good spring water, bottled water or glass-distilled water (no chlorine, no traces of heavy metals); 

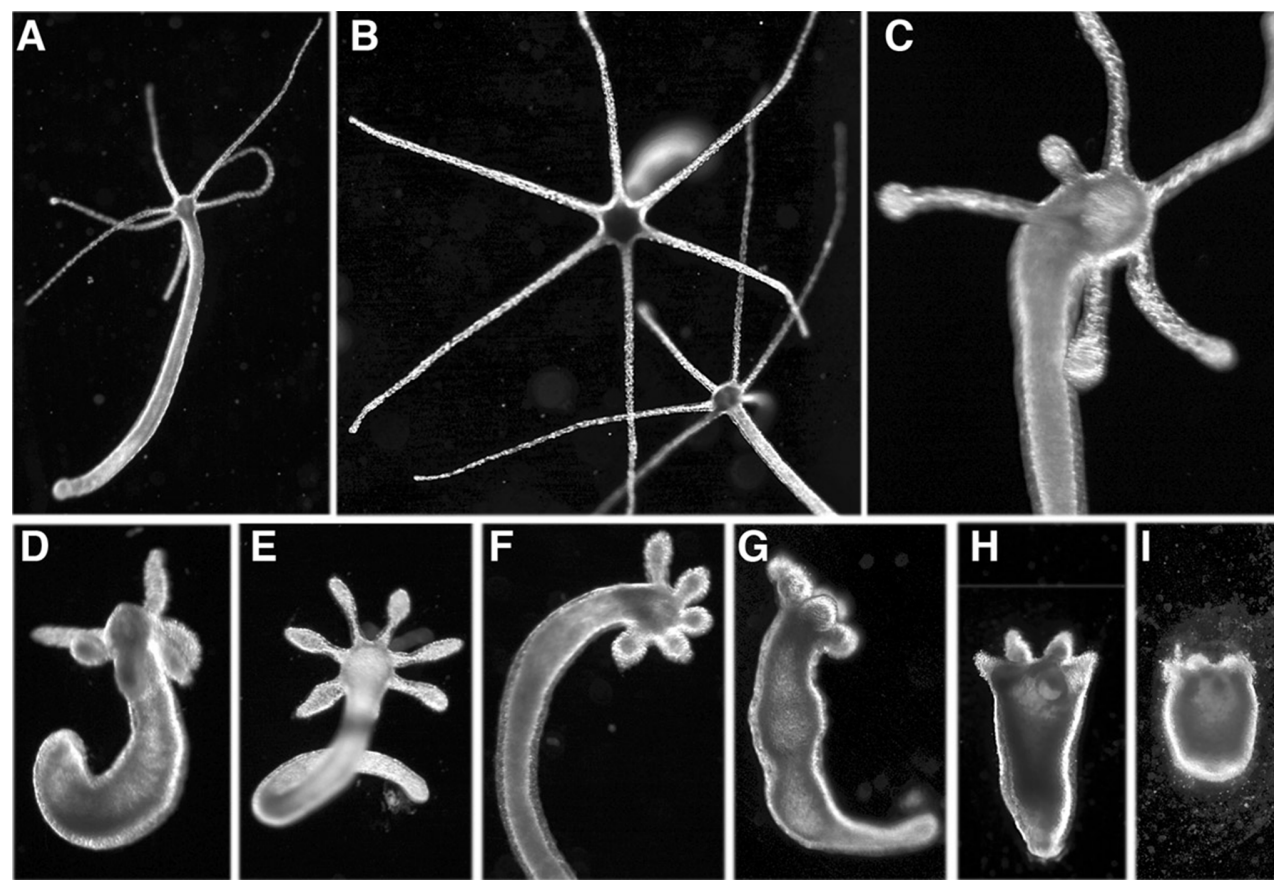

Fig. 2. Assessing Hydra health: the Hydra Health Index - HHI - (after Johnson and Gabel, 1983). Five health states are depicted here: healthy (A,B), early depression (B), advanced depression(D-F), pre-dissociation $(\mathbf{G}, \mathbf{H})$ and dissociating (I). Fasted healthy Hydra have thin and extended tentacles that are 'pointy' at the tip (A,B). The early reversible signs of 'depression' are recognized by examining the tips of the tentacles that show rounded knobs (C-E). At this stage the body column is not affected but progressively tentacles become extremely short, providing a "flower" phenotype corresponding to the loss of the feeding behavior (E-F). Subsequently the body column stays contracted and the animal size is drastically reduced $(\mathbf{G}, \mathbf{H})$. This state is most often ifreversible, it precedes the complete loss of tentacles and the dissociation. Note in (I) the cells that detach from the animal. If many animals in a culture are dissociating, healthy and depressed animals should be immediately removed and kept separately in multi-well dishes for several days. Meanwhile, dissociated animals should be systematically discarded and the culture dishes thoroughly washed as dissociated polyps are highly toxic for the culture. Only healthy animals as depicted in $(A, B)$ should be used for experiments.

2) a room maintained at moderate temperature $\left(17^{\circ} \mathrm{C}-23^{\circ} \mathrm{C}\right)$; 3) glassware that must be new or autoclaved, without any traces of detergents. Hydra can be maintained at room temperature (RT), however a more controlled temperature environment is best for long-term culture. If access to a temperature controlled chamber is not feasible, then an inexpensive wine cooler set for red wine will provide $18^{\circ} \mathrm{C}$ and this is quite agreable to the Hydra.

\section{Materials}

Hydra from academic or commercial sources: All University laboratories that make daily use of Hydra usually provide animals for teachers. The easiest thing to do is to visit their lab webpage (as an alternative contact the authors of this special issue). Commercial suppliers provide another source: In the US - Connecticut Valley Biological Company Inc. and Carolina Biological Company Inc.

Lyophilized stocks of Artemia eggs: These can be found or ordered from most aquarium shops. For large amounts producers can be contacted in www.saltlakebrineshrimp.com, or www. artemia-international.com. These stocks can be stored for months (follow guidelines of the supplier).

Pyrex dishes to place Hydra: square Pyrex dishes are inexpensive compared to commercial culture bowls (Fig. 4A). Dishes should be covered with loose covers, so that gas exchange can occur.

Glass Pipettes: Pasteur pipettes should be fire polished so that sharp edges do not wound the animals in routine manipulations. Larger glass pipettes may be used for aerating the Artemia culture and are required for transferring batches of Hydra during the washing procedure (see Protocol 2, Step 2b).

Chemicals: ethanol, $\mathrm{NaCl}, \mathrm{CaCl}_{2}, \mathrm{KCl}, \mathrm{MgSO}_{4}, \mathrm{HCl}$.

Protocol 1 Preparing Hydra Medium (HM)

Various mineral salts are added to high-quality water to produce a Standard Hydra Medium. The "M" medium from (Muscatine and Lenhoff, 1965) modified by (Sugiyama and Fujisawa, 1977) is widely used and easy to prepare. Its final composition contains $1 \mathrm{mM}$ Tris, $1 \mathrm{mM} \mathrm{NaCl}, 1 \mathrm{mM} \mathrm{CaCl}, 0.1 \mathrm{mM} \mathrm{KCl}, 0.1 \mathrm{mM}$ $\mathrm{MgSO}_{4}$, final $\mathrm{pH} 7.6$.

STEP 1: Prepare 3 separate stock solutions that can be stored at RT (each to be diluted 500x):

Solution A: $0.5 \mathrm{M} \mathrm{CaCl}_{2}, 0.5 \mathrm{M} \mathrm{NaCl}, 0.05 \mathrm{M} \mathrm{KCl}$;

Solution B: $0.5 \mathrm{M}$ Trizma base $(\mathrm{pH} 7.7$ adjusted with $\mathrm{HCl})$;

Solution C: $0.05 \mathrm{M} \mathrm{MgSO}_{4}$.

STEP 2: Autoclave the stock solutions for 15 minutes and store them at RT.

STEP 3: For each liter of HM add in the following order, $2 \mathrm{ml}$ stock $A, 2 \mathrm{ml}$ stock $B, 2 \mathrm{ml}$ stock $\mathrm{C}$. Stir for at least 10 minutes.

Protocol 2 Preparing Artemia for Hydra feeding and washing Artemia free of salt (Fig. 3)

STEP1: Prepare "continental" seawater by adding $33 \mathrm{~g} \mathrm{NaCl}$ in 1 liter of tap water.

\section{STEP2: Hatch Artemia (1 to 2 days)}

2a: A simple method for hatching Artemia is to fill an oblong Pyrex dish about $3 / 4$ full with the Artemia hatching solution then sprinkle a 'pinch' of the dried eggs over the surface. The surface area will provide enough oxygen so that aeration is unnecessary. If a controlled temperature chamber $\left(30^{\circ} \mathrm{C}\right)$ is unavailable, an incandescent light bulb will provide enough heat to produce a hatch overnight. The quality of the hatch will determine how many eggs to sprinkle on the surface. Too many eggs on the surface will result in a low overall hatch since many will die before they can be harvested. The hatching dish should be thoroughly washed between hatches using spring or distilled water and rubbing the surface of the dish with fingers.

$2 \mathrm{~b}$ : Alternatively hatch the Artemia eggs in a bottle prefilled 
with seawater and maintain a constant aeration with a pipette or a tubing connected to a pump that will bubble from the bottom of the solution (Fig. 3). The bottle should be placed close to a light source; the hatching time will depend on the temperature of the room, usually 2 days at $20-22^{\circ} \mathrm{C}$. If possible, place the bottle in a water bath maintained at $28^{\circ} \mathrm{C}$ for a 24 hours hatching.

STEP 3: Wash Artemia thoroughly to get them free of salt before feeding Hydra.

3a. Artemia are strongly attracted to light. So if hatching is performed in the pyrex dish (Step 2a), a focused light should be put at a corner of the dish. After 10 minutes, hatched Artemia may be collected from this corner with a large glass pipette and

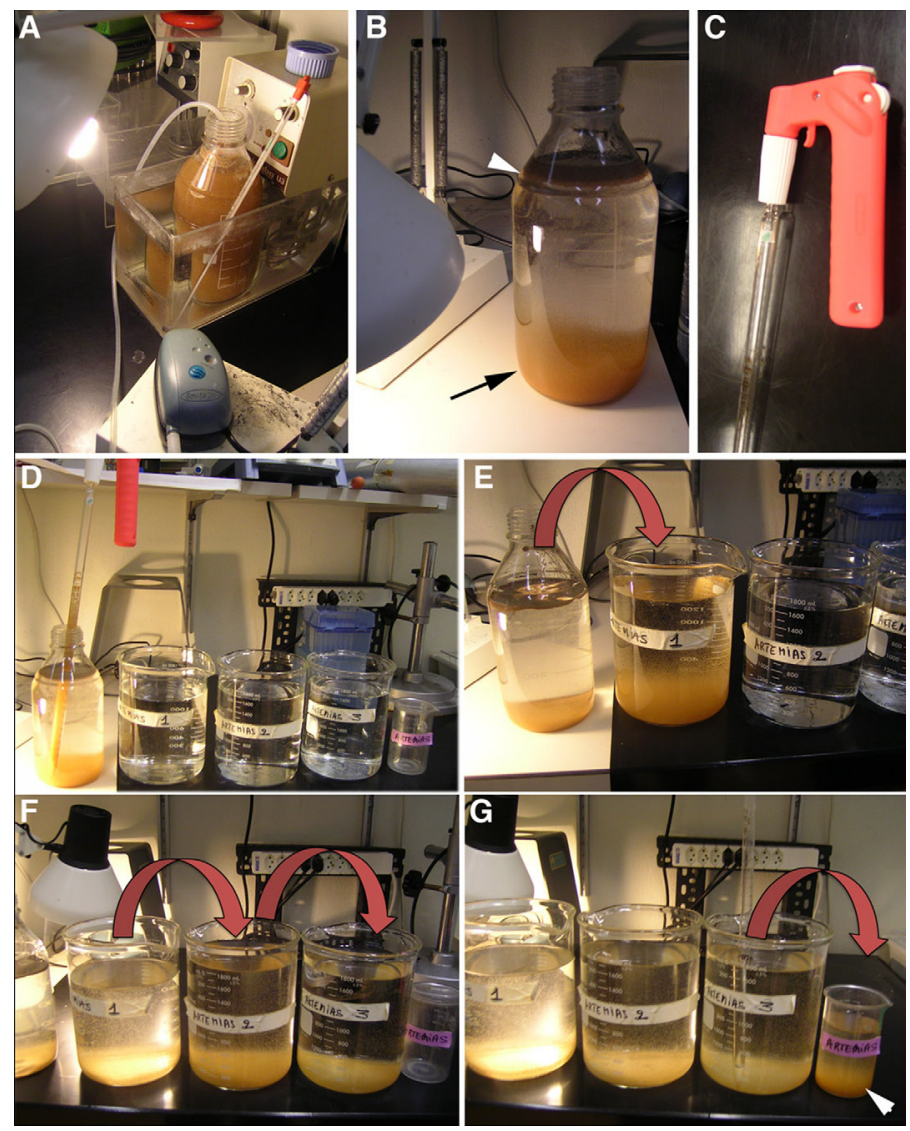

Fig. 3. Artemia culture and preparation of $\boldsymbol{H y d r a}$ food. (A) Facility to obtain hatched Artemia: a one liter glass bottle, submerged in a water bath maintained at $28^{\circ} \mathrm{C}$, is continuously aerated with a glass pipette attached to a tubing connected to an air pump. A light is placed in the proximity of the bottle, although not too close to prevent excessive heating of the Artemia culture. (B,C) After 24 hours the air pump is turned off to collect hatched Artemia, which in a few minutes accumulate closest to the light at the bottom of the bottle (black arrow), while unhatched eggs rise to the surface (white arrowhead). Hatched Artemia form an orange mass that is collected with a $25 \mathrm{ml}$ long glass pipette (C). Care should be taken to harvest only the hatched Artemia as Hydra cannot digest unhatched eggs. (D-G) Procedure to desalt hatched Artemia: transfer them in a 2 liter beaker prefilled with Hydra medium (HM), let them accumulate at the bottom (E); repeat the transfer procedure through two other 2 liter beakers also prefilled with HM (F, G). The complete procedure takes about 20 minutes. Finally Artemia that are now $100 \%$ hatched and desalted can be collected in a small beaker; arrowhead in (G). Verify at the stereomicroscope their fitness, i.e. all swimming. placed in a beaker of prefilled with $\mathrm{HM}$ or spring water. When the Artemia again move toward a light source, they can be removed to fresh $\mathrm{HM}$ and this repeated until the brine shrimps have been thoroughly washed free of the salt solution in which they were hatched. This maximizes getting healthy nauplii and minimizes taking un-hatched eggs that Hydra will consume but not digest.

3b. A faster method for separating salt from shrimp involves the use of any netting (Fig. 4E) that allows the salt solution to pass through but retains the Artemia for further washing. Brine shrimp caught in the net (180 $\mu \mathrm{m}$ mesh) must be thoroughly washed preferably in HM then decanted into 'dedicated glassware' (e.g. small beaker) and then fed to Hydra with a clean Pasteur pipette. The netting should be rinsed thoroughly in spring water, distilled water or HM before and after each use.

Protocol 3 Feeding Hydra and cleaning Hydra to remove all traces of dead Artemia (Fig. 4)

STEP 1 Hydra feeding

Use a Pasteur pipette dedicated to the feeding and change it frequently to minimize contamination of Hydra with pathogens coisolated with Artemia. Feeding is best done at the same time each morning by lightly spreading a small quantity of freshly hatched and thoroughly rinsed nauplii over the surface of the culture. Any brine shrimp not eaten will die in the freshwater medium, thus over feeding leads to contamination with bacterial and fungal infections that can compromise Hydra health.

STEP 2 Hydra cleaning

2a. One to four hours after feeding, a first wash is accomplished by pouring the contents of the culture bowl into a 1 liter beaker filled with normal culture medium (2 liters if the culture is large). Swirl the beaker and remove the Hydra at the center with a large glass pipette and transfer them to a $600 \mathrm{ml}$ beaker. Swirl the beaker and remove the Hydra at the center. Repeat the process in a third $600 \mathrm{ml}$ beaker then return the cleaned Hydra to the original culture dish. Periodically all Hydra should be removed from the stock dish so that it can be thoroughly cleaned as described previously.

2b. Approximately 8 hours after feeding, Hydra will expel undigested remains of the Artemia. A second washing is therefore strongly recommended. A perfect routine would be to feed Hydra at $8 \mathrm{am}$, first wash at noon and final wash at the end of the school day. The final wash can be accomplished in the same way as the first but examination of the culture dishes and the Hydra health should make it clear when a complete change of culture dish is necessary. A plastic scraper (Fig. 4E) can be used to gently separate all Hydra from a dish so that they can be transferred to another.

2c. The Pasteur pipettes used to transfer Hydra should be stored in a test tube with ethanol then rinsed with water or $\mathrm{HM}$ before use. If multiple strains are present, culture bowls and pipettes should be color coded with tape so that strains are not co-mingled. Indeed Hydra frequently adhere to the body of the pipette and then might inadvertently be transferred from one culture to another if pipettes are used interchangeably. Between uses the dishware should be washed with a small amount of detergent, rinsed extensively with water to remove any trace of detergent, rinsed in ethanol and allowed to dry completely so that the ethanol evaporates before reuse (Fig. 4D). 


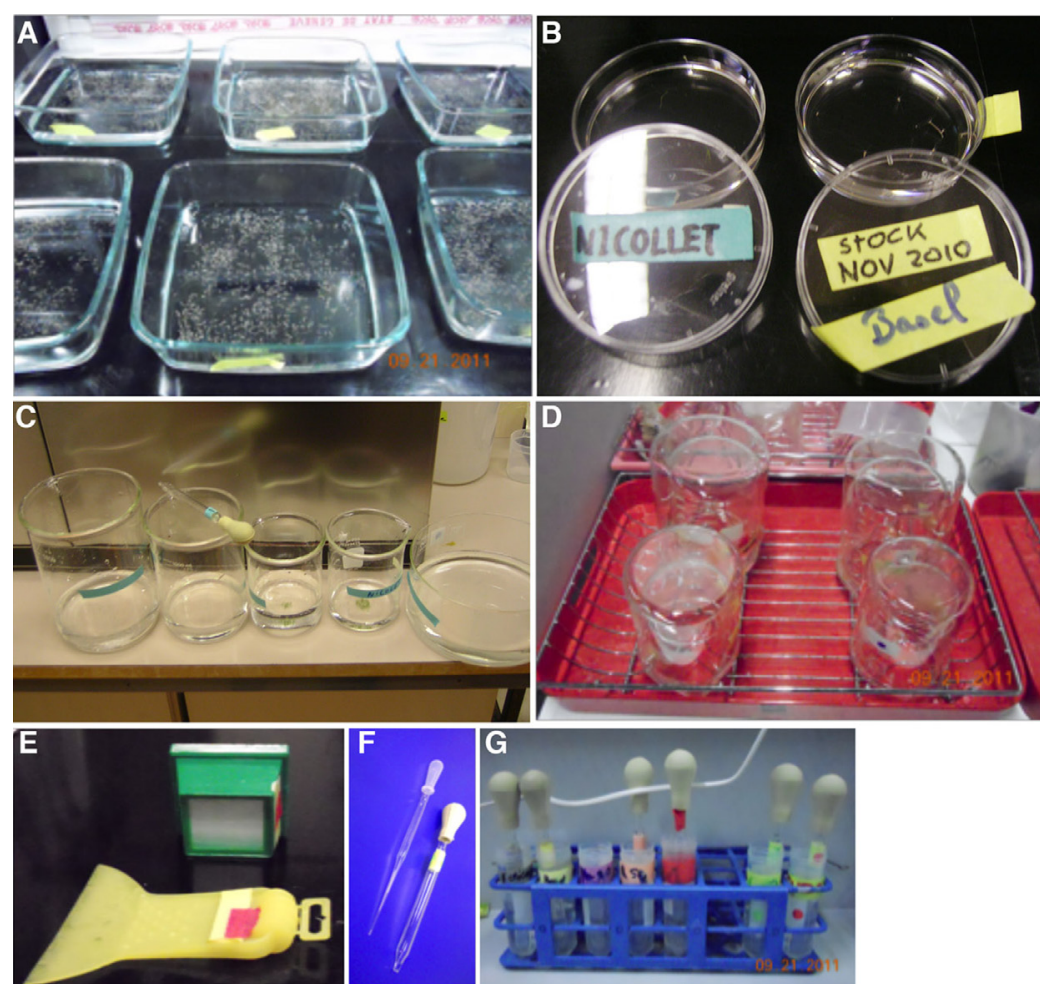

Fig. 4. Daily maintenance of Hydra culture. (A) Hydra mass cultures are maintained in Pyrex culture dishes (about 500 Hydra per $25 \mathrm{~cm} \times 25 \mathrm{~cm}$ dish) and fed at least twice a week with a Pasteur pipette (F, left). (B) Smaller cultures can be kept in plastic Petri dishes (chose untreated plastic), 6 or $10 \mathrm{~cm}$ diameter. In this case, Hydras are manipulated with Pasteur pipettes, previously briefly exposed to fire to round the tip. (C) 6 to 8 hours after feeding, the medium is poured through a filter that retains Hydra but not the Artemia; see in (E) the 300 um mesh filter from Hobby Dohse; the dishes are rinsed three times with tap water and refilled with HM. In parallel Hydra collected on the filter are transferred to a 2 liter glass beaker and washed by successive transfers into at least 3 smaller beakers with the help of a large glass pipette ( $F$, right). When necessary, all animals are gently detached with a soft scraper (E), washed in successive beakers and transferred to new dishes. Filters are not used when the animals are not fit but instead are separated from Artemia by repeated washing in clean beakers (D). The dishware is washed with a limited amount of detergent, rinsed extensively with water and finally briefly with ethanol before it is allowed to dry. Occasionally dishes and beakers are autoclaved (D,F,G). A specific set of pipettes, dishware, and filters are used for each strain (labeled with a color code). After use the glass pipettes are rinsed with water and stored loaded with ethanol in plastic tubes containing ethanol (G).

\section{Student corner - the simplest experiment: do Hydra respond to light?}

The youngest students can readily observe the photic

Student corner - the simplest experience: observe the predator's attack

The programmed feeding response in Hydra is extraordinary. Present a drop of Artemia onto a slide with Hydra in a drop of HM and students will be amazed to see the immediate awakening of the seemingly inert polyp. The tentacles will begin to writhe and coil; actively swimming Artemia that come in contact with them will suddenly cease all movement. If sufficient brine shrimp are added, the Hydra will appear to have developed a cap adorned with ornaments - the paralyzed brine shrimp. In a matter of minutes careful observation will show the tentacles contracting to bring the brine shrimp toward the conical protrusion containing the mouth. The mouth will open and in within 20 minutes (or sooner) the Hydra will be engorged with brine shrimp. The number eaten can often be counted. Counts of how many are eaten, how long it takes for complete ingestion to occur, whether the size of the Hydra is related to how many are eaten are all simple extensions of this 'simple experience'.

\section{Photobiology of Hydra}

\section{Key concepts: extraocular light sensing, phototaxis}

Hydra without differentiated sense organs is nevertheless remarkably responsive to light. A rhodopsin like protein, localized in the ectodermal layer, was identified in Hydra vulgaris (Santillo et al., 2006). Normal behavior is characterized by an endogenous cycle of shortening and elongation (Passano and McCullough, 1962) that is modulated by pulses of light (Taddei-Ferretti et al., 1987). Another overt response to light is a phototactic movement. Studies with Hydra vulgaris show a strong positive response to blue light (Passano and McCullough, 1964; Passano and McCullough, 1965) and blindness to red light (Passano and McCullough, 1963; reviewed in Taddei-Ferretti and Musio, 2000). response of Hydra by taking a cardboard box, cutting a small hole in one side and inverting the box over a bowl of Hydra. The concept of control can be introduced by inverting a similar box but without the hole over another bowl of Hydra. Within 24-48 hours healthy Hydra will accumulate on the side of the dish closest to the light while controls in the dark will remain randomly distributed. The experiment can become semi quantitative using a simple technique originally described by (Pardy, 1976). The entire experiment can be completed in 4-5 days and is suitable students in middle school or secondary school.

\section{Materials}

- $9 \mathrm{~cm}$ plastic Petri dishes

- black paint

- black tape

- 40-watt fluorescent-cool-white lamps

Protocol 4 Measuring Hydra's phototactic behavior - according to Pardy (1976) (Fig. 5)

STEP 1: Paint the outside of a $9 \mathrm{~cm}$ plastic Petri dish black on the outside. Add an additional layer of black tape to the outside, if necessary, to prevent the entry of all light.

STEP 2: Do the same with the cover to the Petri dish except leave a central circular window or port with a diameter of $1.0 \mathrm{~cm}$. STEP 3: Make a measurement grid on the cover of another Petri dish by making concentric rings $1.2 \mathrm{~cm}$ apart. Number the rings 1 to 4 with 1 being the outermost ring and 4 being the central disc located directly under the transparent port (the area of each ring is $4.5,12.128 .8,30.9 \mathrm{~cm}^{2} 1-4$ respectively).

STEP 4: To test for phototactic activity, place $10-20$ Hydra randomly in the dishes prefilled with $\mathrm{HM}$ and allow them to settle and attach. 
STEP 5: After the polyps have attached (at least 1 hour) put the lids in place and orient the dishes $75 \mathrm{~cm}$ under 40 watt fluorescent cool-white lamps.

STEP 6: At 24 hour intervals remove the lids of the experimental dishes and replace with the grid made from a Petri dish cover. STEP 7: Record the number of Hydra in each ring with the plastic grid in place.

\section{Going further - introducing variables: light color, nutrition, symbiosis}

Explore Effects of Light Color

In order to explore the effect of light color on phototactic behavior in Hydra a high school student in New York modified the Petri dish light grid (Fig 5 A,B). Healthy, budless Hydra viridissima from stocks that were fed on a regular schedule (e.g. three times a week) were selected. The Hydra were placed in $\sim 11 \mathrm{~cm}$ diameter (4.5") culture bowls filled with $200 \mathrm{ml} \mathrm{Hydra} \mathrm{medium} \mathrm{to}$ minimize change in temperature during the experiment. Either a red, blue or green filter was placed over the light port between the 40-watt fluorescent cool-white lamps. An infrared absorbing filter was placed over the color filter. Students should be encouraged to design and make their own 'light grid'.

\section{Materials (Purchased to modify Protocol 4)}

Filters: Red (700 nm), blue (450 nm) green (525 nm) and infrared absorbing filters

http://www.hoyaoptics.com/color_filter/index.htm.

Culture bowls and thermometer

http://www.carolina.com/product/equipment+and+supplies/ glass+and+plasticware
Protocol 5 Making a light grid and measuring phototaxis

STEP 1: Paint the glass culture bowl black on the outside leaving the bottom clear. Add an additional layer of black tape to the outside, if necessary, to prevent the entry of all light.

STEP 2: Place a light grid scaled from 4 to 1 (Fig. 5A) under each bowl and fill the bowl with $200 \mathrm{ml} \mathrm{HM}$.

STEP 3: Place 10 budless green Hydra in Ring 2 of each culture bowl, allowing the Hydra to settle and attach before placing a light-blocking lid over the bowl.

STEP 4: After the lid is in place, place the color filter over the light port (Fig. 5B).

STEP 5: Place an infrared absorbing filter over each color filter.

STEP 6: Place the 40-watt fluorescent-cool-white lamps over the light ports (Fig. 5B).

STEP 7: After 24 hours and at the same time each day thereafter for 4 days, remove the filters and lid and record the number of Hydra in each ring. Record the temperature of the medium each day at the same time.

STEP 8: Replace the lid and filters exactly as before removal.

\section{Comparing green vs. brown Hydra}

Phototactic movements: In five independent experiments where 10 green and 10 brown Hydra were used in each experiment, the student found a strong 'photophobic' response to red light for green (H. viridissima) but not for brown ( $H$. vulgaris). Only the data for green Hydra are shown in Fig. 5C.

Influence of light on a developmental process: If healthy, 24hour fasted, budless Hydra from stocks feed three times per week are selected for the experiment, budding is likely to occur over the course of four days. Compare the number of buds produced in green
Fig. 5. Effect of light color on phototaxis and budding rate in the symbiotic green Hydra viridissima. $(\mathbf{A}, \mathbf{B})$ Equipment and setting used for the phototaxis experiments: the three distinct color light filters, the Pyrex bowls painted in black except the bottom that covers a grid with 4 concentric circles, a lid on each bowl with a small hole in the center, the 40-watt fluorescent cool-white lamps (see Protocol 5).(C,D) All experiments were performed on budless Hydra viridissima fasted for $24 \mathrm{hr}$ with 10 animals per condition exposed to lights emitting at three different wave lengths: $450 \mathrm{~nm}$ (blue), $525 \mathrm{~nm}$ (green), $700 \mathrm{~nm}$ (red). (C) Phototactic responses of green Hydra to distinct light colors. In five independent experiments, green Hydra placed in Ring 2 of the 'phototactic' chamber (Protocol 5) showed a strong positive response to blue light $1450 \mathrm{~nm}$, average position 3.8 0.3) and a 'photophobic' response to red light (700 nm, average position 1.3 r 0.3) after four days. Mean values and standard deviations of the sum of all experiments are indicated above corresponding arrows. This is in contrast to brown Hydra that are 'blind to red light' (Passano and McCullough 1963) as confirmed in our experiments (data not shown). (D) Bud production of green Hydra placed in distinct lights. In eight independent experiments, the number of buds produced by Hydra exposed to light with distinct wavelengths was recorded after 4 days. In green Hydra, bud production was stimulated by blue light $(450 \mathrm{~nm})$ and inhibited by red light $(700 \mathrm{~nm})$. Mean values and standard deviations of the sum of all experiments are indicated above corresponding arrows.
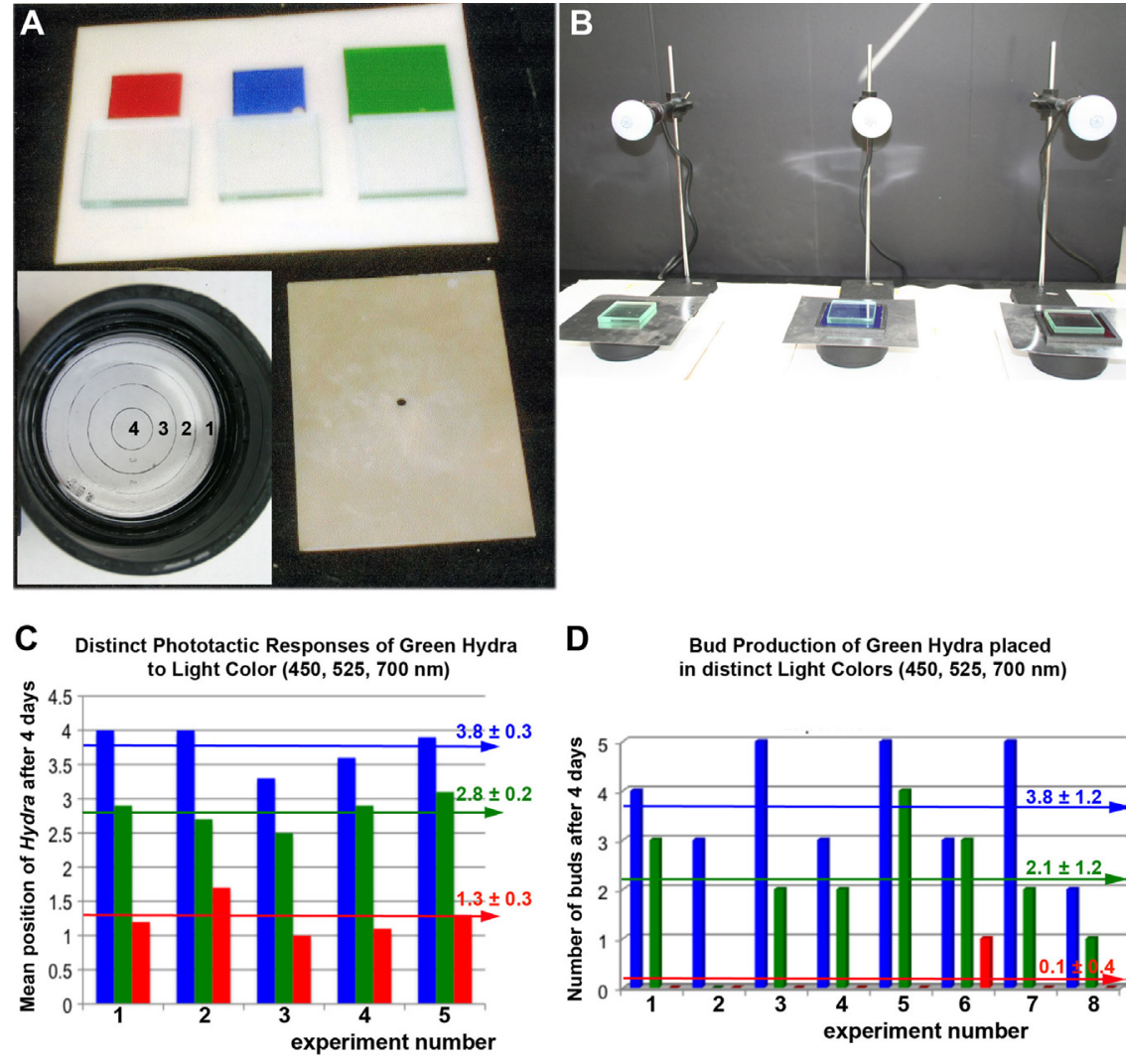

D

Bud Production of Green Hydra placed in distinct Light Colors $(450,525,700 \mathrm{~nm})$

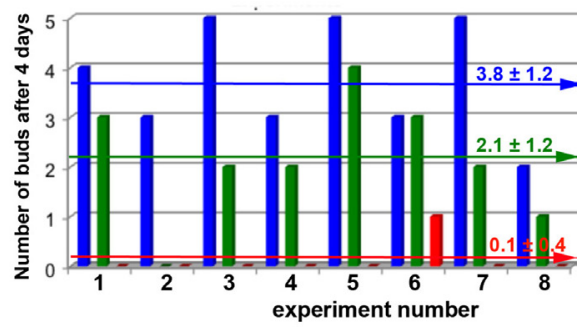


vs. brown Hydra as a function of wavelength. In eight independent experiments the student found an inhibition of budding in red compared to blue light for green $(H$. viridissima) but not for brown (H. vulgaris). Only the data for green Hydra are shown in Fig. 5D.

\section{Comparing nutritional condition on Hydra's response to light}

If healthy Hydra are starved it may be possible to see differences in their phototactic behavior. Clearly one expects prolonged starvation to be detrimental to phototactic movement, but can the presence of the endosymbiotic algae found in green Hydra ameliorate the effect of starvation? Pilot studies with young students (13-14 years old) indicated that this might be so (Bossert, personal observation).

\section{Applied ecology}

\section{Key concepts: bioremediation, bioassay, toxicology}

Originally developed by Johnson and Gabel $(1982,1983)$ to compare the effects of toxicants on adults vs. embryos (i.e. adult Hydra vs. re-aggregating cells), the $\mathrm{HHI}$ has also been used in a variety of bioassays to rapidly assess the quality of freshwater (Beach and Pascoe, 1998; Pardos et al., 1999; Pascoe et al., 2003; Arkhipchuk et al., 2006). Hydra sensitivity to cadmium and zinc is comparable with published values for other invertebrate and vertebrate species (Holdway et al., 2001) while in many earlier studies Hydra was among the most sensitive species to metals tested (Browne and Davis, 1977; Stebbing and Pomroy, 1979; Holdway, 1991; Hyne et al., 1992; Pollino and Holdway, 1999; for recent update see in this issue the review by Quinn et al., 2012).

\section{Student corner - the simplest experiment: using the Hydra bioassay to demonstrate fast remediation by Duckweed (Lemna sp.)}

Students can use the $\mathrm{HHI}$ to rapidly screen water for toxicants after bioremediation (Fig. 6). For example, the ability of common duckweed (Lemna sp found in almost all ponds) to remove lead

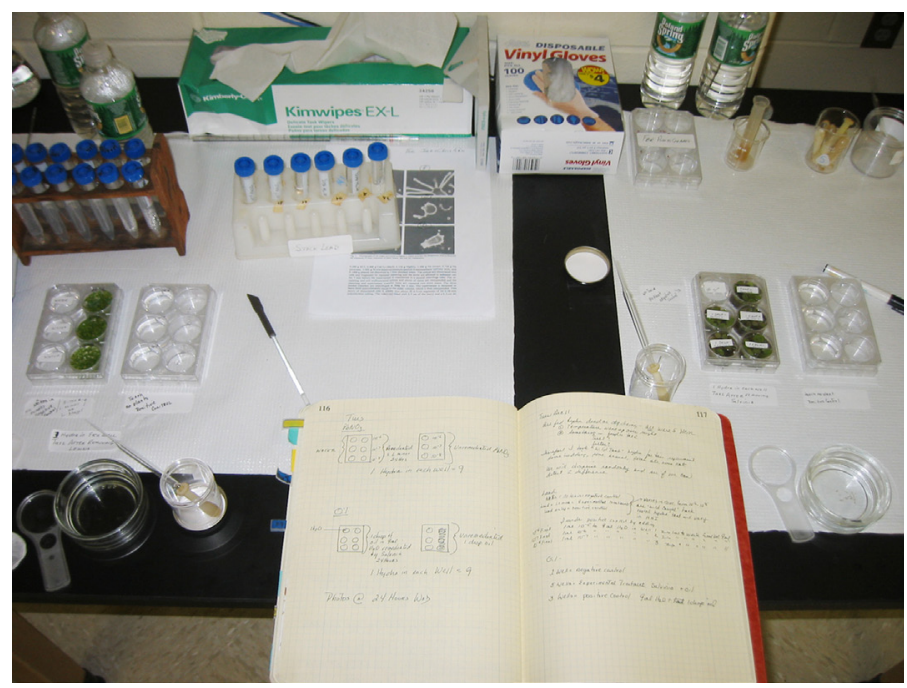

Fig. 6. From a student's bench. The basic materials for the Hydra bioassay used by a high school student to assess lead remediation by Lemna sp. The animals can be observed with magnifying glasses as shown here but also with a stereomicroscope, which is useful to precisely define the observed phenotypes. from water could rapidly and clearly be demonstrated in a simple experiment that can be completed in 24 hours. Again, with appropriate supervision even young students can do this.

\section{Materials}

Chemicals: Lead nitrate stock solution. An Adult Supervisor should prepare the stock solution. See: http://cartwright. chem.ox.ac.uk/hsci/chemicals/lead_nitrate.html

Sterile Costar 6 well plates: www.sigmaaldrich.com/labware/ labware-products.html

Lemna (duckweed): Duckweed can be found in most ponds but they are also available commercially in the US from Connecticut Valley Biological Co. Inc. and Carolina Biological Company Inc.

Personal Protective Equipment for students: protective eyewear, non-latex gloves, lab coats

Protocol6-Using the HHI to detect accumulation of lead by Lemna STEP 1: Prepare a $500 \mu \mathrm{M}$ stock solution of $\mathrm{Pb}\left(\mathrm{NO}_{3}\right)_{2}$

STEP 2: Add $10 \mathrm{ml}$ of diluted lead stock solution to 5 wells of a sterile Costar 6 well plate - suggested concentration range from $0.1 \mu \mathrm{M}$ to $20 \mu \mathrm{M}$. Place $10 \mathrm{ml} \mathrm{HM}$ in each well of a 6 well plate. STEP 3: Repeat the process for a second 6 well dish.

STEP 4: Add Lemna to all lead containing wells in one of the two dishes

STEP 5: Remove Lemna after 24 hours and have students record $\mathrm{HHI}$ for normal controls versus remediated and un-remediated lead contaminated medium.

\section{Going further}

Protocol 7 Outline for quantification of bioremediation study

A high school student was able to detect lead concentration as low as $0.06 \mu \mathrm{M}(20 \mu \mathrm{g} / \mathrm{L})$ using the $\mathrm{HHI}$ and measuring lead concentration with a LeadTrak Test Kit (see basic equipment in Fig. 6). She was also able to demonstrate the effect of lead on Hydra health in a dose dependent manner that varied with both Lemna species and Hydra species. Hydra oligactis were more sensitive to lead than Hydra vulgaris (Fig. 6).

\section{Protocol 8 Outline for application of bioassay to field study}

The Hydra bioassay was applied to a field study where water had been previously collected from various points along the Hudson River in New York State (Slobodkin, unpublished). As one component of his project, a student identified and revisited a site of pollution (Sleepy Hollow, N.Y.) that had been documented some 10 years previously. When he applied the Hydra Health Index, he found the site uncontaminated. He traced the original source of toxicants as likely to come from housing development that occurred coincident with the first testing.

\section{Ecology and evolution}

Key concepts: selection pressure, adaptation, role of predator in community structure, energy allocation, evolution

A Simple Introduction to Ecology and Evolution: The first (and generally last) encounter many students have with Hydra is to observe its predatory behavior when presented with either brine shrimp or Daphnia. While predatory behavior is, in itself, fascinating this demonstration can be turned into a lesson introducing 
ecology and evolution to even very young students. For example, if both Daphnia and brine shrimp are placed on the 'Hydra menu' what will happen? Certainly these Artemia will meet these Hydra for the first time in evolutionary history on your student's bench. They have no defense for the offensive weapons of Hydra and will immediately be paralyzed and ingested - often in great numbers. Hydra nematocysts have an amazing array of toxins that are currently being characterized along with body cells producing non-nematocystic toxins (Sher and Zlotkin, 2009), see in this issue (Rachamim and Sher, 2012). While Daphnia is susceptible to Hydra toxins, its morphology makes it a more difficult meal to capture and ingest compared to brine shrimp (Rabus and Laforsch, 2011). Certainly, even the youngest students can compare the outcome of the encounter and be encouraged to ask questions rather than simply observe Hydra's predatory behavior with only one type of prey.

The cladocerans Daphnia and Simocephalus are common inhabitants of freshwater ponds and lakes. Daphnia are primarily planktonic whereas Simocephalus are more common in the littoral zone. Daphnia are susceptible to Hydra toxin whereas Simocephalus is immune to it. In controlled experiments, Schwartz et al., showed that in the absence of Hydra, Daphnia out competes Simocephalus but when Hydraare added, the outcome is reversed and now Simocephalus out competes Daphnia. It was hypothesized that the evolution of an energetically expensive trait (e.g. antivenom) permitted Simocephalus to deter littoral zone predators (e.g. Hydra), whereas Daphnia have not invested in this defense and therefore have more energy available for reproduction and are thus able to exclude Simocephalus in the absence of Hydra (Schwartz and Herbert, 1989).

\section{Student corner - the simplest experiment: does the presence of Hydra alter populations in two types of Cladocera?}

This complex ecological interaction (i.e. role of predator in community structure) illustrates the ideas of selection pressure, energy allocation, adaptation and ultimately evolution. The concepts can be introduced by using Hydra to alter the population dynamics of Daphnia and Simocephalus in the laboratory classroom. The rationale for the protocol that follows is based on the key concepts described above. The students will set up a competition 'arena' consisting of plastic cups equally filled with normal HM.

Cup 1 - Interspecies Competition Cup contains three Daphnia and three Simocephalus (each with eggs visible).

Cup 2 - Predator Prey Interaction Cup contains a non-budding Hydra $(H$. oligactis recommended) in addition to three Daphnia and three Simocephalus (each with eggs visible).

Cup 3 - Daphnia Control Cup contains six Daphnia (with eggs visible).

Cup 4 - Simocephalus Control Cup contains six Simocephalus (with eggs visible).

The hypothesis to be tested is that the presence of Hydra will change the number of survivors when the 'predator cup' is compared the controls. For example, in the absence of a predator (Cup 1) Daphnia should increase in number compared to Simocephalus but when Hydra is present (Cup 2) Simocephalus should increase in number compared to Daphnia (see Key Concepts for rationale). Cup 3 and 4 are controls for Cups 1 and 2 and data should be normalized against the number of each species in Cup 3 and 4 at the end of the experiment.

\section{Materials}

- Small plastic cups or bowls to accommodate $100 \mathrm{ml}$ of media.

- Algal cultures. These are easy to grow (see Dodson, 2009 for algal culture methods), or can be purchased from Connecticut Valley Biological Co. Inc. or Carolina Biological Co. Inc.

- Daphnia, Lemna and Hydra are readily available in the US from Connecticut Valley Biological Co. Inc. and from Carolina Biological Co. Inc. and are also easily collected along the edges of ponds. A simple guide to pond water organisms can be used to distinguish Simocephalus from Daphnia or standard Internet search of images can also be used.

- Simocephalus (Clinging daphnia - Simocephalus vetulus) can be ordered at: www.aquaculturestore.com/fwinverts.html

Protocol 9 The competition experiment (after Schwartz et al., 1989) STEP 1: Fill cups with $100 \mathrm{ml}$ Hydra medium or pond water.

STEP 2: Interspecies Competition Cup. Add three gravid Daphnia and three gravid Simocephalus.

STEP 3: Selective Predator Cup. Do the same as above but also add one budless Hydra.

STEP 4: Daphnia Control Cup. Add six gravid Daphnia.

STEP 5: Simocephalus Control Cup. Add six gravid Simocephalus. STEP 6: Add the same amount of algae to each cup each week for five weeks.

STEP 7: Record the number of individuals of each species in each cup weekly for one to five weeks.

Going further-challenge the student to design the experiment

Rather than providing a step-by-step protocol, present students with the 'Key Concepts' section and challenge them to design the appropriate experiment. This, of course, is a valuable experience on it's own. Data analysis for this experiment will be a challenge. Will students understand the need for Cups 3 and 4 ? Why are gravid Daphnia and Simocephalus used? Should the number of eggs in each individual be the same? Should the number of eggs be recorded prior to selection for inclusion in the experiment? Why should there be algae in each cup? How will the amount of algae be standardized? If the algae settle to the bottom of the cup how will they be resuspended equally in all cups?

\section{Developmental biology: regeneration}

\section{Key concepts: the head regeneration process from wound healing to patterning}

The regeneration process in Hydra is a platform for the exploration of many of the most intriguing questions in all of biology. How do wounds heal? How does the wound not only heal, but also replicate the lost structures? What is the role of stem cells in this process? How do morphogenic gradients and axial patterning modify the regeneration response? (Bode, 2012; Shimizu, 2012). Head regeneration is well documented from Trembley's original experiment to the modern synthesis of the cellular and molecular events that drive the process (Holstein et al., 2003; Galliot and Chera, 2010). In essence it involves the transformation of a piece of gastric tissue into an organizer that recruits stem cells and progenitors to rebuild the missing structure (see next section, and also reviews by Bode and by Shimizu in this issue). After decapitation an alternative program likely makes use of the cell plasticity, the possibility for some differentiated cells to change their fate (transdif- 
ferentiation). As the genes encoding the components of the main signaling pathways are very well conserved from Hydra to mammals, understanding the cellular and molecular mechanisms driving head regeneration is of great interest to cell and developmental biologists. With healthy Hydra even young students can explore discrete variables. For example temperature, starvation, presence of algal endosymbionts (Bossert and Slobodkin, 1983), formation of buds will affect the kinetics of regeneration (see below).

\section{Student corner-the simplest experiment: recording the kinet- ics of head regeneration}

Materials for cutting and staging Hydra

Pasteur pipettes (before use expose shortly the tip to fire to abrade it) and bulbs

Use covers of $9 \mathrm{~cm}$ plastic Petri dishes for cutting Hydra

$9 \mathrm{~cm}$ plastic Petri dishes for early regeneration (take only bacterial grade Petri dishes)

6 well plates for staging Hydra (not treated for cell cultures)

Regeneration data recording sheet (Fig. 7)

Sterile scalpel blades with handles already attached

Stereomicroscope (if possible with dark background)
Protocol 10 Stage head regeneration in Hydra (Fig. 7)

DAY 1

STEP 1: For a single experiment, select at least 30 budless Hydra that have been fasted for at least 24 hours (length of starvation is a variable that will affect regeneration kinetics).

STEP 2: Place 30 polyps in the cover of a $9 \mathrm{~cm}$ diameter Petri dish filled $\mathrm{HM}$.

STEP 3: Using a sterile scalpel and cut the polyps either below the tentacles ( $80 \%$ body length) or through the mid-body $(50 \%)$ Remove the upper body parts to follow only head regeneration for this experiment and transfer the lower body parts to a $9 \mathrm{~cm}$ Petri dish prefilled with $30 \mathrm{ml} \mathrm{HM}$, cover. Always keep at least $1 \mathrm{ml} / \mathrm{Hy}$ dra during the early phase of the regeneration test: It is important to keep this dilution as the products released into the media by wounded animals inhibit head regeneration when too concentrated (Kaloulis et al., 2004).

STEP 4: At RT the regeneration process will be rapid; count the animals and perform the first staging as early as $6 \mathrm{hpa}$, then on the second day every 2 or 3 hours.
Fig. 7. Perform head regeneration experiments with Hydra. (A) Staging of head regeneration. Animals are observed live under a stereomicroscope equipped with a cold light to prevent excessive heating. Immediately after bisection the lower halves take a "hammer" shape; at this early stage the animals exhibit a regular contractile activity to close the wound but never fully extend (stage 1). Atstage 2, the animals take a tube shape with a closed and smooth apical extremity; given the regular body contractions, they can be fully elongated or more contracted (see two aspects of the same animal). At stage 3, the body shape is similar to that of stage 2 but the apical extremity becomes flattened (arrowheads); this stage is very transient, visible for a few hours. At stage 4, the first tentacle rudiments emerge (arrow). At stage 5, at least two tentacles are longer than the diameter of the hypostome (this should be observed on fully extended animals). At stage 6, head regeneration is close to completion as most tentacles are elongated and the animal can now efficiently catch preys. (B,C) At each time point, the animals are sorted according to their regeneration stage in a 6-well dish and counted. A typical record datasheet is shown in $C$, ready to be used at the first time point after bisection (T1). (D) Head regeneration kinetics recorded at $R T\left(23^{\circ} \mathrm{C}\right)$ for 30 healthy Hydra vulgaris (Basel strain). Animals were 24 hour fasted and each of them was with one mature bud at the time of cutting. Bisection level was at the upper third of the body column lapproximately $65 \%$ using base as reference point of $0 \%$ so that cut severs animal midway between the mature bud and the hypostome, see Protocol 10). (E) Regeneration curves in lipoic acid (LA) treated Hydra showing the LA-induced inhibition of head regeneration. Half the animals were cut in HM supplemented with $L A$ $(25 \mu \mathrm{m})$ and left in the drug for 4 hpa while the other half were cut in HM. Except for the initial drug treatment (0-4 hpa) where both controls and drug treated animals were crowded (30 animals per $10 \mathrm{ml})$, animals were then left in $1 \mathrm{ml} \mathrm{HM}$ per animal to regenerate.
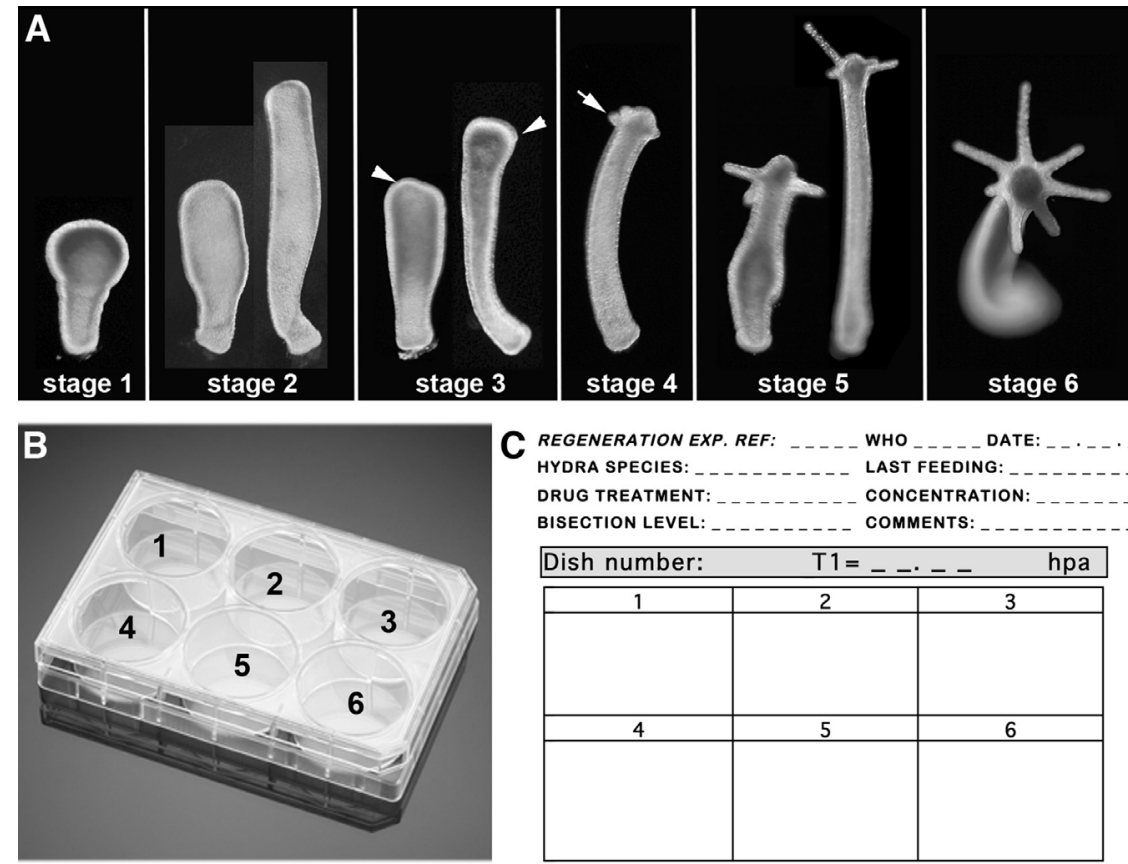

C regeneration exp. Ref: HYDRA SPEOIES: DRUG TREATMENT: WHO

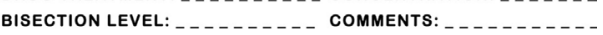
\begin{tabular}{|c|c|c|}
\hline Dish number: & \multicolumn{2}{c|}{$\mathrm{T1}=\ldots \ldots$} \\
\hline 1 & 2 & hpa \\
\hline & & \\
& & \\
\hline 4 & 5 & 6 \\
\hline & & \\
& & \\
\hline
\end{tabular}

D

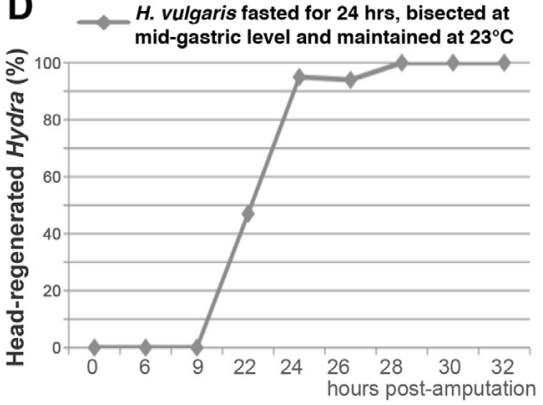

E

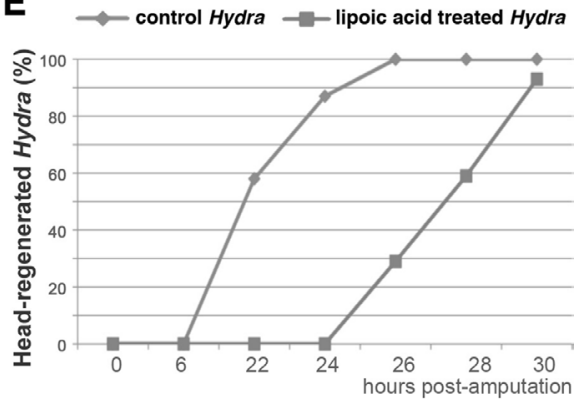




\section{DAY 2}

STEP 5: Number each well of the plate 1 through 6 (see Fig. 7G) and fill each well with $8 \mathrm{ml} \mathrm{HM}$.

STEP 6: At regular time points starting 20 hours post-amputation (hpa) starting at least 20 hours after amputation, observe the regenerating bodies and record the degree of regeneration by placing each Hydra in a well of the 6 well plate corresponding to the stages of regeneration as shown in Fig. 7 A-F.

\section{DAY 3}

STEP 7: At convenient intervals (usually every 2 hours) continue with the staging process, progressively moving animals from one well to another as they advance in stage. Continue staging for at least 72 hpa.

STEP 8: Analyze the kinetics of head regeneration by summing the number of animals in Stages $4+5+6$ divided by the total number of animals in the sample (e.g. 30) for each staging time point.

STEP 9: Graph the data (see the curve of the control animals in Fig. 7H for a sample result)

NOTE: At $\mathrm{RT}\left(\sim 23^{\circ} \mathrm{C}\right)$ regeneration will be rapid, but much slower at $18^{\circ} \mathrm{C}$. Therefore it is advisable to make a schedule so that students can stage the animals every two hours at the time tentacle rudiments appear. Sequential cuttings allow successive groups of students to record and analyze data.

\section{Going further - challenge the student to design an authentic investigation by introducing variables to alter regeneration kinetics}

Once the basic process of staging normal regeneration is understood, students can conduct independent investigations by introducing a variable. In this context Protocol 10 is used except that normal Hydra regeneration is compared to an experimental group treated with the introduced variable. For example one group of Hydra can be cut at $50 \%$ while another is cut at $80 \%$ or one population of Hydra might be kept at RT while another is kept in an $18^{\circ} \mathrm{C}$ 'wine cooler', or one can compare head regeneration in budless polyps versus polyps developing early stage buds. Indeed the presence of buds can affect regeneration dramatically. If an immature bud (see (Otto and Campbell, 1977) for bud staging) is forming when the parent is cut there is a competition between the apical hypostome and the newly forming axis such that the head regeneration process is 'stacked' or inhibited by the developing bud.

Student corner - the molecular signaling at work during regeneration: does lipoic acid inhibit head regeneration in Hydra?

One way to test the molecular signaling involved in the head regenerative process is to test pharmacological agents that affect one or the other signaling pathway. Lipoic acid is a normal metabolite found in mitochondria where it aids pyruvate dehydrogenase in the oxidation of pyruvate that enters the tri carboxylic acid cycle. It is reported to inhibit regeneration in Hydra (Ham and Eakin, 1958; Eakin, 1961). The simplest experiment requires preparation of stock solutions of lipoic acid and relies on timed observations of regeneration subsequent to cutting. Budless $24 \mathrm{hr}$ fasted Hydra are bisected and then 'staged' over 72 hours using the descriptive photographs and compared to appropriate controls (Fig. 7). Once the general technique is mastered, other metabolites may be tested for their effect on regeneration.
Materials

Prepare $1 \mathrm{ml}$ of a stock solution of $1 \mathrm{M}$ lipoic acid (Sigma T1395) in $100 \%$ ethanol

Store this solution at $4^{\circ} \mathrm{C}$ refrigerator. Do not freeze

Eppendorf tubes - to store $1 \mathrm{M}$ stock lipoic acid

$100 \%$ ethanol

Micropipettes (and tips) at $10 \mu$ l volume

$100 \mu \mathrm{M}$ working solution (add $4 \mu \mathrm{l}$ of $1 \mathrm{M}$ stock to $40 \mathrm{ml} \mathrm{HM}$ ) for each student

$50 \mathrm{ml}$ sterile plastic tubes to store $40 \mathrm{ml}$ of $100 \mu \mathrm{M}$ solution of lipoic acid for each student

$6 \mathrm{~cm}$ plastic Petri dishes for cutting Hydra (take only bacterial grade Petri dishes)

For the rest of the material, see Protocol 10

Protocol 11 The lipoic acid $(L A)$ regeneration experiment

DAY 1

STEP 1. Have students decide what constitutes an appropriate control for this experiment and have them prepare it (e.g. $40 \mathrm{ml} .01 \%$ $\mathrm{EtOH}$ and $40 \mathrm{ml} \mathrm{HM}=$ Controls for $100 \mu \mathrm{M}$ LA in $40 \mathrm{ml} \mathrm{HM}$ ). Store in refrigerator if the experiment is not done on the same day.

STEP 2: Bring test solutions to same temperature as Hydra culture media.

STEP 3: Bisect Hydra at mid body in $10 \mathrm{ml}$ test media in $6 \mathrm{~cm}$ plastic dishes (e.g. $10 \mathrm{ml} 100 \mu \mathrm{M} \mathrm{LA} ; 10 \mathrm{ml} \mathrm{HM} ; 10 \mathrm{ml} \mathrm{0.01 \%} \mathrm{EtOH)} \mathrm{Use}$ no more than 30 animals per $10 \mathrm{ml}$ for this step.

STEP 4: 4 hours after bisection transfer both halves to $9 \mathrm{~cm}$ Petri dishes with at least $1 \mathrm{ml} \mathrm{HM}$ per regenerating animal.

\section{DAY 2, DAY 3, DAY 4}

STEP 5: Students score the emergence of tentacle rudiments on all Hydra in each treatment using a 6 well plate for staging as described above. For each condition, the total number of animals needs to be recorded for each interval where staging occurs (e.g. 6, 20, 22, 24 and 26 hpa.

STEP 6: Students record data in Excel and use simple graphic analysis to see if Hydra exposed to lipoic acid regenerate the head more slowly when compared to untreated controls. For each time point of a given experiment, the students will calculate the ratio obtained between the summing the number of Hydra in stages $4+5+6$ and dividing that total by the total number of bisected animals. A sample assay is seen in Fig. 7E.

\section{Going further: what is the effect of timing of drug treatment on the head regeneration process?}

It is possible to modify the experiment above so that one student group exposes Hydra to the drug 0-4 hpa while another exposes the Hydra to the drug 5-9 hpa. Since the high school day rarely permits a 9-hour experiment, volunteers (most likely the teacher) would transfer regenerates to recovery media for staging after the 5-9 hour drug treatment. The original experiments (Eakin and Ham 1958; Eakin 1961) report that the inhibitory properties of lipoic acid disappear if animals are cut and allowed to regenerate normally for 5 hours before exposure to the drug. This has never been replicated but is amenable to study by motivated students. This is still and open and interesting question, the answer to which may help us understand the mechanism of the drug's effect. 
Alternatively and following the same principles the students might test other drugs that affect specific signaling pathways (for review see (Galliot, 2012). Indeed the MEK inhibitor UO126 (20 $\mu \mathrm{M})$ given for three hours at the time of bisection inhibits head but not foot regeneration after mid-gastric bisection (Kaloulis et al., 2004). Similarly the Src tyrosine kinase inhibitor PP2/AG1879 (1 $\mu \mathrm{M})$, the ERK 1,2 inhibitor Apigenin (6.6 $\mu \mathrm{M})$, the Pi3K inhibitor LY294002 or the PKC inhibitors Staurosporine (100 nM) Sphingosine $(2 \mu \mathrm{M})$ all inhibit head but not foot regeneration when given continuously after decapitation (Cardenas et al., 2000; Cardenas and Salgado, 2003; Arvizu et al., 2006; Manuel et al., 2006).

\section{Developmental biology: discovering what an organizer is}

Key concepts: detection of an organizer activity through transplantation experiments

At the beginning of the $\mathrm{XX}$ century Ethel Browne Harvey, at that time PhD student in the laboratory of Thomas Morgan, discovered the principle of "organizer activity" thanks to the grafting experiments she performed on Hydra polyps. Her aim was as she explains "to discover what material when grafted would give, the necessary stimulus to call forth the development of a new Hydranth". For that purpose she decapitated a green polyp (Hydra viridis) and then cut out a quarter of the head, like a piece of pie, keeping a tentacle on this piece as a marker to follow the evolution of the graft. She then immediately inserted this piece into a slit performed on the body column of a host polyp from the same species and observed in the following days the formation of a secondary axis (Fig. 8). Thanks to grafting experiments performed between pigmented and un-pigmented Hydra, she nicely demonstrated that the graft recruits cells from the host (Browne, 1909), a property that defines organizers as later established by Hans Spemann and Hilde Mangold in embryos (Spemann and Mangold, 1924).

\section{Student corner - the simplest experiment: what is the result of grafting a piece of hypostome on a host?}

\author{
Materials for grafting experiments \\ Two pairs of clamps \\ A scalpel and razor blades \\ A stereomicroscope \\ Petri dishes $6 \mathrm{~cm}$ diameter \\ Methylene Blue 1\% aqueous solution
}

Protocol 12 The grafting experiment (Fig. 8)

STEP 1: Decapitate the donor Hydra below the tentacle ring;

STEP 2: Stain the decapitated head with methylene blue for about 30 min, subsequently rinse in $\mathrm{HM}$ until the medium remains clear; STEP 3: Dissect a fraction of the head to provide "a piece of pie" that includes one tentacle.

STEP 4: Make a longitudinal slit on the body column of the host through the two cell layers and insert immediately the graft.

\section{Going further - challenge the student to design distinct graft- ing experiments}

Multiple variations can be performed on this type of lateral transplantations: the grafted tissue can be isolated from different regions along the body axis, or from a regenerating tip or from the presumptive head of a budding polyp. Each of these tissues can induce the formation of a secondary axis although with different properties (Bode, 2012; Shimizu, 2012). Also a tissue from a given origin can be grafted at different positions along the body column of the host. The rate of success in inducing the formation of an extra axis will vary and the student will actually evidence the presence of a head inhibitory activity produced by the host, which is graded along the body column, maximal at the apical pole and minimal at the lower level. Thus when grafting is technically reproducible, quantitative analyses of the head organizer and head inhibitory activities can be obtained. Such approaches that nevertheless might exceed the level of experiments performed in a classroom, are recapitulated in (Shimizu, 2012).

\section{Cell biology}

Key concepts: all basic cell types shared by eumetazoans can be found in Hydra

Hydra belongs to Cnidaria, a phylum that diverged later than Porifera and occupies a sister position to bilaterians (see trees in the review by Steele (2012). Interestingly cnidarians, ctenophores and bilaterians, a group named "eumetazoans", make use of the synaptic neurotransmission to sense and respond to their environment.

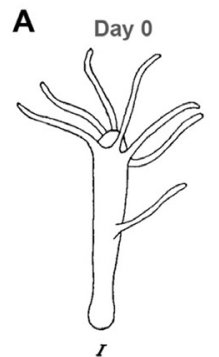

B

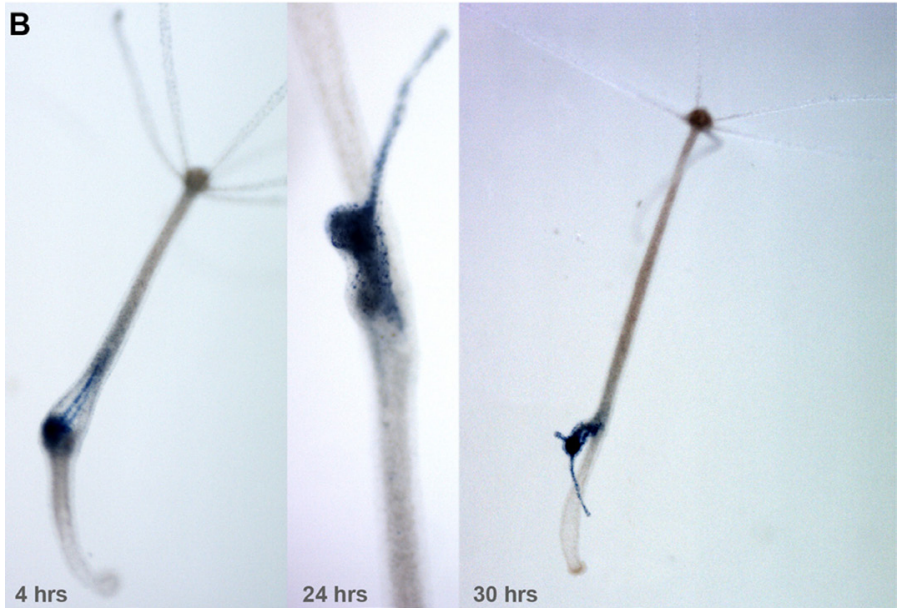

Fig. 8. Head-organizer activity evidenced in lateral transplantation experiment. (A) Lateral transplantation experiment performed on Hydra viridis as initially reported by Ethel Browne in 1909; 10/13 grafts induced the formation of an ectopic axis (Browne, 1909). (B) Lateral transplantation experiment performed 101 years later on Hydra vulgaris, between a methylene blue stained graft and an unstained host. Four hours after grafting the graft is firmly inserted, note the blue tentacle that is visible on the backside of the animal. 24 hours after grafting, an ectopic axis is developing, here composed of blue-labeled endodermal cells and ectodermal cells mostly unstained. 30 hours after transplantation, tentacles emerge at the tip of the ectopic axis. 


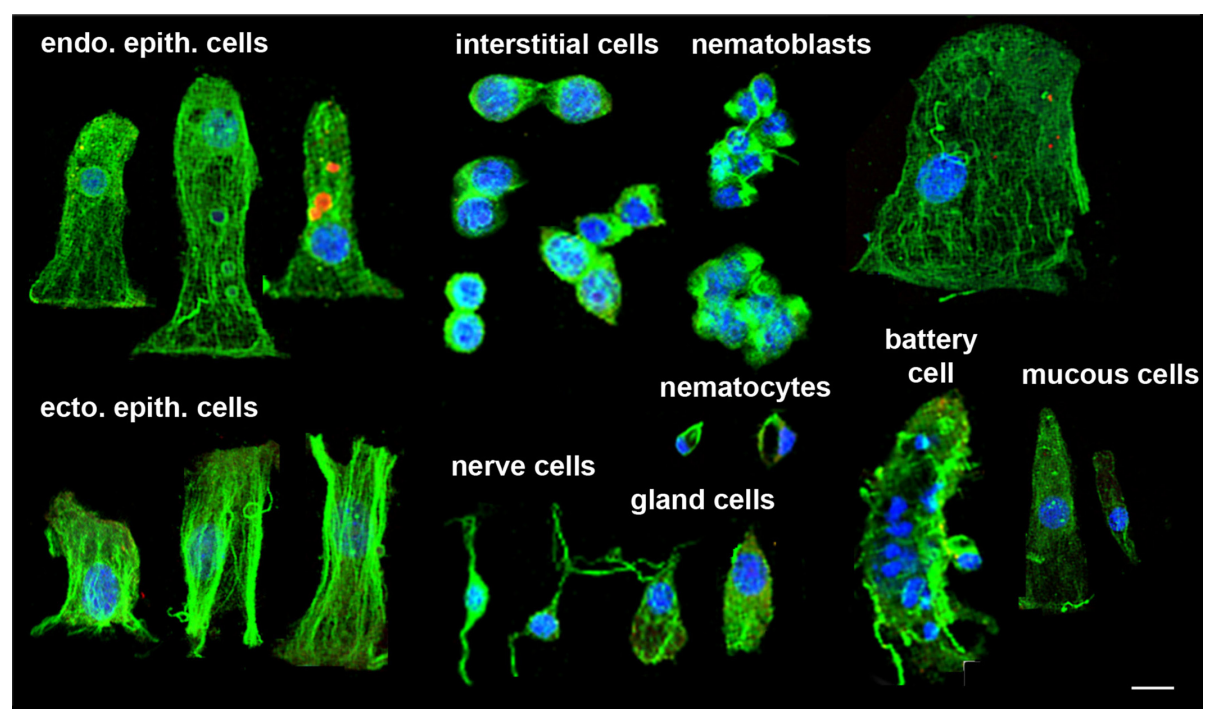

Fig. 9. Identification of the various cell types in Hydra. Macerated tissues were immunostained with the anti $\alpha$-tubulin antibody that labels the cytoskeleton of the cells and stained with DAPI that interacts with DNA. Scale bar: $4 \mu \mathrm{m}$.

This is not the case of Porifera (sponges) that do not differentiate true nervous systems. Therefore it is possible to trace in cnidarians the first evolved nervous system (Anderson, 1989; Koizumi, 2002; Galliot et al., 2009; Galliot and Quiquand, 2011). Indeed an analysis of the various cell types found in Hydra, i.e. stem cells, epithelial cells, neurons, gland cells, germ cells, demonstrates what it takes to make a 'modern eumetazoan' (David, 2012; Hobmayer et al., 2012; Nishimiya-Fujisawa, 2012). An examination of Hydra cells thus provides a clue to the continuity of life that is so evident at the molecular level (Arendt, 2008). Sharing this fundamental insight with students is a valuable lesson. Slides of intact Hydra cells (macerates) are easy to prepare and store. Students can compare the cells they see in the slides they prepare with the photographic guide (Fig. 9, see also in Holstein and Emschermann (1995); Hobmayer et al. (2012).

\section{Student corner-identification of the various celltypes in Hydra Materials}

- Photographic guide to Hydra cells provided

- Microscope with Oil Immersion Lens recommended.

- Maceration Fluid (David, 1973): 7\% glycerol, 7\% acetic acid in HM

- $1.5 \mathrm{ml}$ eppendorf tubes

- Pasteur pipettes and bulbs

- 100 - $200 \mu l$ micropipette and tips (optional)

- Glass slides (gelatin coated if possible) and cover slips

- Tween 80 (surfactant) to spread cells (optional) - Sigma-AldrichP6224

- Mounting Medium (e.g. Carolina Biological Co. Inc. Kleermount ${ }^{\circledR}$, in Xylene or Mowiol 4-88 - Polysciences, Inc.-)

Protocol 13 Maceration of Hydra tissues (David 1973)

STEP 1: Take 5 intact animals and place them in a $1.5 \mathrm{ml}$ eppendorf tube. Wash briefly in $\mathrm{HM}$ and remove the liquid as much as possible. STEP 2: Add $50 \mu$ l of maceration fluid.

STEP 3: When the tissues begin to disassociate into cells, very gently aspirate up and down to enhance dissociaton.

STEP 4: Let the macerate sit at RT for 15 to 30 minutes; flick the tube from time to time.

STEP 5: Add a drop of $10 \%$ Tween 80.

STEP 6: Homogenize the cells by pipetting gently and spread on a glass slide.

STEP 7: Let the slides dry at least overnight or better over a weekend at RT. Alternatively you can let the slides dry on heating plate at $30^{\circ} \mathrm{C}$ for 2 hours then ready to use

STEP 8: Stain the dried cells for 10 min with a Toluidine blue solution. In case you have access to a fluorescent microscope, stain the nuclei with DAPI (UV excitation, blue light emission), the actin fibers with phalloidin (red light emission)

STEP 9: Add a drop of mounting medium and a cover slip. Let dry ON. Such slides can be stored at $-20^{\circ} \mathrm{C}$ for years without any deterioration.

STEP 10: Examine macerates using 40x or $63 x$ magnifiying objectives. Identify the main cell types.

\section{Going further - a look at cellular complexity in Hydra}

Protocol 14 Recognizing the various cell types and their spatial distribution along the polyp

The Hydra body column is formed of two walls of myoepithelial cells, the endoderm and the ectoderm separated by an extracellular layer named mesoglea. These two types of myoepithelial cells can easily be distinguished on macerated tissues, as the former are rather cubic when the latter are elongated with a clear apico-basal polarity (Fig. 9). The central part of the animal contains an excess of stem cells compared to the extremities where cells stop dividing and terminally differentiate (David and Plotnick, 1980; Bode, 1996a). Indeed in the body column, stem cells self-renew, produce progenitors that migrate towards the extremities and terminally differentiate. An easy way to observe this highly dynamic maintenance of the pattern in adult polyps is to macerate separately the apical, the mid-gastric and the basal regions.

For this purpose 15 to 20 animals are bisected twice, once at about $80 \%$ body length (in the upper body column) and in the peduncle region. The three parts are collected and macerated separately. Then students will be able to recognize in the midgastric body column the abundant pairs of large i-cells, the clusters of nematoblasts that divide synchronously, the rather cubic ectodermal epithelial cells, the elongated endodermal epithelial cells (also named digestive cells) that contain numerous digestive vacuoles if animals were recently fed. In the apical region beside the numerous nerve cells, either sensory cells or ganglia neurons, they will identify the unusual ectodermal epithelial cells that in the tentacles differentiate into large battery cells loaded with nematocytes ready to discharge. In intact nematocytes they will be able to identify the capsule, named nematocyst, and the moon-shaped nucleus compressed by this huge capsule; in discharged nematocytes they will see the typical lasso (Beckmann and Ozbek, 2012). In cells of the lower region of the animal they will notice the numerous dividing progenitors located in the peduncle, the mucous ectodermal cells specific of the basal disk. 
Protocol 15 Detection of symbioticalgae in cells of Hydra viridissima Maceration of green Hydra ( $H$. viridissima) will enable students to see Chlorella-like algae inside the endodermal cells. The number of algae per cell tends to be constant for a given strain. Various manipulations can alter the number of algae per cell. Students can test the effect of starvation, dark, and decapitation. The latter event will normally result in a dramatic increase in the number of algae per cell by 12 hours after cutting. By 24 hours the number will return to uncut control levels but only for the smallest strains of green Hydra. The possible evolutionary significance of this is discussed in Bossert and Dunn (1986) and Kovacevic (2012).

\section{Conclusions and perspectives}

The biology of Hydra spans the normal secondary school curriculum and beyond. While it is clearly desirable to include living organisms in the teaching of biology, the demands on teacher time often squeezes the 'life' out of the study of life. It need not be so. Healthy Hydra polyps are readily available commercially in the US and from universities in Europe. With patience they are readily cultured. It is hoped that this article will motivate and enable teachers to bring Hydra into the classroom, not only to enhance normal curricula but also to permit collaborative investigations based on problem solving rather than classic expository pedagogy.

Students recognize the words "regeneration, wound healing and cancer". They perceive these as one might when observing only the tips of the fingers; that is as separate entities. With the ongoing exploration of the Hydra model, the next generation of young students may understand that at the molecular level these processes are like the fingers that are extensions of the hand. That is, if we trace the fingers back we find one hand, one 'molecular milieu' with highly conserved pathways underlying these seeming disparate events. In a small but growing number of secondary schools and summer enrichment programs, students are doing PCR and RTPCR. Using primers for detecting the regulation of Hydra genes that are clearly related to human homologues has already begun in this context. Hopefully these studies, and the ones described here, will build upon the foundation laid by Abraham Trembley to motivate a new generation to study this organism that has the potential to teach us so much on so many levels.

\section{Acknowledgements}

The authors are grateful to Lisbeth Muster, Joana Cruz and Denis Benoni for excellent daily care of the Hydra cultures, to Wanda Buzgariu for providing the cellular analysis shown here. Patricia Bossert thanks all the students who showed patience, motivation and intelligence especially Rushan Guan, Alicia Munson and Jason Schloss whose research is described here. This work was supported by the Canton of Geneva, the Swiss National Science Foundation, the National Center of Competence in Research (NCCR) "Frontiers in Genetics" (pilot project "Stem cells and regeneration"), the Georges and Antoine Claraz donation.

\section{References}

ANDERSON, P.A., BOUCHARD, C. (2009). The regulation of cnidocyte discharge. Toxicon 54: 1046-1053.

ANDERSON, P.A.V. (1989). Evolution of the First Nervous Systems. Plenum Press, New York.

ARKHIPCHUK, V.V., BLAISE, C., MALINOVSKAYA, M.V. (2006). Use of hydra for chronic toxicity assessment of waters intended for human consumption. Environ Pollut 142: 200-211.
ARVIZU, F., AGUILERA, A., SALGADO, L.M. (2006). Activities of the protein kinases STK, PI3K, MEK, and ERK are required for the development of the head organizer in Hydra magnipapillata. Differentiation 74: 305-312.

BEACH, M.J., PASCOE, D. (1998). The role of Hydra vulgaris (Pallas) in assessing the toxicity of freshwater pollutants. Water Research 32: 101-106.

BECKMANN, A., OZBEK, S. (2012). The Nematocyst: A molecular map of the cnidarian stinging organelle. Int J Dev Biol 56: 577-582.

BODE, H.R. (2012). The head organizer in Hydra. Int J Dev Biol 56: 473-478.

BODE, H.R. (1996a). The interstitial cell lineage of hydra: a stem cell system that arose early in evolution. J Cell Sci 109 (Pt 6): 1155-1164.

BODE, H.R. (1996b). The interstitial cell lineage of hydra: a stem cell system that arose early in evolution. J Cell Sci 109: 1155-1164.

BOSCH, T.C., ANTON-ERXLEBEN, F., HEMMRICH, G., KHALTURIN, K. (2010). The Hydra polyp: nothing but an active stem cell community. Dev Growth Differ52: 15-25.

BOSCH, T.C., KRYLOW, S.M., BODE, H.R., STEELE, R.E. (1988). Thermotolerance and synthesis of heat shock proteins: these responses are present in Hydra attenuata but absent in Hydra oligactis. Proc Natl Acad Sci USA 85: 7927-7931.

BOSSERT, P. (1987). The Effect of Hydra Strain Size on Growth of Endosymbiotic Algae, Department of Ecology and Evolution. State University of New York, Stony Brook.

BOSSERT, P., DUNN, K.W. (1986). Regulation of intracellular algae by various strains of the symbiotic Hydra viridissima. J Cell Sci 85: 187-195.

BOSSERT, P., SLOBODKIN, L.B. (1983). The Effect of Fast and Regeneration in Light vs. Dark on Regulation in the Hydra-Algal Symbiosis. Biol Bull 164: 396-405.

BRENNECKE, T., GELLNER, K., BOSCH, T.C. (1998). The lack of a stress response in Hydra oligactis is due to reduced hsp70 mRNA stability. Eur J Biochem 255: 703-709.

BROWNE, C.L., DAVIS, L.E. (1977). Cellular mechanisms of stimulation of bud production in Hydra by low levels of inorganic lead compounds. Cell Tissue Res 177: 555-570.

BROWNE, E.N. (1909). The production of new hydranths in hydra by the insertion of small grafts. J Exp Zool 7: 1-37.

CAMPBELL, R.D. (1987a). The Hydra of Madagascar (Cnidaria: Hydrozoa). Zool J Lennean Soc 91: 253-263.

CAMPBELL, R.D. (1987b). A new species of Hydra (Cnidaria: Hydrozoa) from North America with comments on species clusters within the genus. Zool J Lennean Soc 91: 253-263.

CARDENAS, M., FABILA, Y.V., YUM, S., CERBON, J., BOHMER, F.D., WETZKER, R., FUJISAWA, T., BOSCH, T.C., SALGADO, L.M. (2000). Selective protein kinase inhibitors block head-specific differentiation in hydra. Cell Signal 12: 649-658.

CARDENAS, M.M., SALGADO, L.M. (2003). STK, the src homologue, is responsible for the initial commitment to develop head structures in Hydra. Dev Biol264: 495-505.

DAVID, C.N. (2012). Interstitial stem cells in Hydra: multipotency and decision-making Int J Dev Biol 56: 489-497.

DAVID, C.N., PLOTNICK, I. (1980). Distribution of interstitial stem cells in Hydra. Dev Biol 76: 175-184.

DODSON, S. (2009). Cladocera and Other Branchiopoda, in Ecology and Classification of North American Freshwater Invertebrates. (THORP, J.H., COVICH, A.P., Eds.). Academic Press, San Diego, California USA, p. 873.

EAKIN, R.E. (1961). Studies on Chemical Inhibition of Regeneration in Hydra, in: The Biology of Hydra and some other Coelenterates. (LENHOFF, H.M., LOOMIS, W.F. Eds.). University of Miami Press Coral Gables Florida, pp. 399-412.

ELLIOTT, J.K., ELLIOTT, J.M., LEGGETT, W.C. (1997). Predation by Hydra on larval fish: field and laboratory experiments with bluegill (Lepomis macro-chirus). Limnol Oceanogr 42: 1416-1423.

GALLIOT, B. (in press). Injury-induced asymmetric cell death as a driving force for head regeneration in Hydra. Dev Genes Evol

GALLIOT, B., CHERA, S. (2010). The Hydra model: disclosing an apoptosis-driven generator of Wnt-based regeneration. Trends Cell Biol 20: 514-523.

GALLIOT, B., MILJKOVIC-LICINA, M., DE ROSA, R., CHERA, S. (2006). Hydra, a niche for cell and developmental plasticity. Semin Cell Dev Biol 17: 492-502.

GALLIOT, B., QUIQUAND, M. (2011). A two-step process in the emergence of neurogenesis. Eur J Neurosci 34: 847-862.

GALLIOT, B., QUIQUAND, M., GHILA, L., DE ROSA, R., MILJKOVIC-LICINA, M., CHERA, S. (2009). Origins of neurogenesis, a cnidarian view. Dev Biol332: 2-24. 
GRIFFING, T.C. (1965). Dynamics and energetics of populations of brown Hydra, PhD thesis, Zoology Department. University of Michigan, Ann Harbor, MI.

HAM, R.G., EAKIN, R.E. (1958). Loss of regenerative capacity in hydra treated with lipoic acid. J Exp Zool 139: 55-68.

HECKER, B., SLOBODKIN, A.B. (1976). Responses of Hydra oligactis to temperature and feeding rate, in Coelenterate ecology and behavior. (MACKIE, G.O., Ed.). Plenum, New York, pp. 175-183.

HOBMAYER, B., JENEWEIN, M., EDER, D., GLASAUER, S., GUFLER, S., HARTL, M. and SALVENMOSER, W. (2012). Stemness in Hydra - a current perspective. Int J Dev Biol 56: 509-517.

HOLDWAY, D.A. (1991). Mining and tropical freshwater environments: laboratory studies. Austral Biol 4: 228-236.

HOLDWAY, D.A., LOK, K., SEMAAN, M. (2001). The acute and chronic toxicity of cadmium and zinc to two hydra species. Environ Toxicol 16: 557-565.

HOLSTEIN, T., EMSCHERMANN, P. (1995). Zytologie, In Cnidaria: Hydrozoa, Kamptozoa. (ZWICK, E.J.S.A.P. Ed.). Gustav Fisher Verlag, Stuttgart, pp. 5-15.

HOLSTEIN, T.W., HOBMAYER, E., TECHNAU, U. (2003). Cnidarians: an evolutionarily conserved model system for regeneration? Dev Dyn 226: 257-267.

HYNE, R., RIPPON, G.D., ELLENDER, G. (1992). pH-dependent uranium toxicity in freshwater Hydra. Sci Total Environ 125: 159-173.

JOHNSON, E.M., GABEL, B.E. (1983). An artificial 'embryo' for detection of abnormal developmental biology. Fundam Appl Toxicol 3: 243-249.

JOHNSON, E.M., GABEL, E.G. (1982). Application of the Hydra Assay for Rapid Detection of Developmental Hazard. Int J Toxicol 1: 57-71.

KALOULIS, K., CHERA, S., HASSEL, M., GAUCHAT, D., GALLIOT, B. (2004). Reactivation of developmental programs: the cAMP-response element-binding protein pathway is involved in hydra head regeneration. Proc Natl Acad Sci USA 101: 2363-2368.

KAWAIDA, H., SHIMIZU, H., FUJISAWA, T., TACHIDA, H., KOBAYAKAWA, Y. (2010). Molecular phylogenetic study in genus Hydra. Gene 468: 30-40.

KHALTURIN, K., ANTON-ERXLEBEN, F., SASSMANN, S., WITTLIEB, J., HEMMRICH, G., BOSCH, T.C. (2008). A novel gene family controls species-specific morphological traits in Hydra. PLoS Biol 6: e278.

KOIZUMI, O. (2002). Developmental neurobiology of hydra, a model animal of cnidarians. Can J Zool 80: 1678-1689.

KOVACEVIC, G. (2012). Value of the Hydra model system for studying symbiosis. Int J Dev Biol 56: 627-635.

LENHOFF, H.M. (1983). Hydra: Research Methods. Plenum Press, New York.

LENHOFF, S.G., LENHOFF, H.M. (1986). Abraham Trembley. Mémoires, Pour Servirà L'histoire d'un Genre De Polypes d'eau Douce, à Bras en Forme de Cornes, Hydra and the Birth of Experimental Biology-1744. The Boxwood Press, Pacific Grove.

LENTZ, T.L. (1966). The cell biology of hydra. North-Holland Publishing company, Amsterdam, Holland.

LOMNICKI, A., SLOBODKIN, A.B. (1966). Floating in Hydra Littoralis. Ecology 47: 881-889.

MANUEL, G.C., REYNOSO, R., GEE, L., SALGADO, L.M., BODE, H.R. (2006). $\mathrm{PI} 3 \mathrm{~K}$ and ERK 1-2 regulate early stages during head regeneration in hydra. Dev Growth Differ 48: 129-138.

MARTINEZ, D.E., INIGUEZ, A.R., PERCELL, K.M., WILLNER, J.B., SIGNOROVITCH, J., CAMPBELL, R.D. (2010). Phylogeny and biogeography of Hydra (Cnidaria: Hydridae) using mitochondrial and nuclear DNA sequences. Mol Phylogenet Evol 57: 403-410.

MUMFORD, E.P. (1940). The present status of studies of faunal distribution with reference to oceanic islands, 6th Pacific Science Congress Berkeley, California, pp. 241-248.

MUSCATINE, L., LENHOFF, H.M. (1965). Symbiosis of hydra and algae. I. Effects of some environmental cations on growth of symbiotic and aposymbiotic hydra. Biol Bull 128: 415-424.

NISHIMAYA-FUJISAWA, C. (2012). Germline stem cells and sex determination in Hydra. Int J Dev Biol 56: 499-508.

OTTO, J.J., CAMPBELL, R.D. (1977). Budding in Hydra attenuata: bud stages and fate map. J Exp Zool 200: 417-428.

OZBEK, S., BALASUBRAMANIAN, P.G., HOLSTEIN, T.W. (2009). Cnidocyst structure and the biomechanics of discharge. Toxicon 54: 1038-1045.
PARDOS, M., BENNINGHOFF, C., GUEGUEN, C., THOMAS, R., DOBROWOLSKI, J., DOMINIK, J. (1999). Acute toxicity assessment of Polish (waste) water with a microplate- based Hydra attenuata assay: a comparison with the Microtox test. Sci Total Environ 243-244: 141-148.

PARDY, R.L. (1976). Light in the biology of green Hydra. In Coelenterate ecology and behavior. (MACKIE, G.O. Ed.). Plenum Press, New York, pp. 401- 407.

PASCOE, D., KARNTANUT, W., MULLER, C.T. (2003). Do pharmaceuticals affect freshwater invertebrates? Astudy with the cnidarian Hydra vulgaris. Chemosphere 51: $521-528$

PASSANO, L.M., MCCULLOUGH, C.B. (1962). The Light Response and the Rhythmic Potentials of Hydra. Proc Natl Acad Sci USA 48: 1376-1382.

PASSANO, L.M., MCCULLOUGH, C.B. (1963). Pacemaker hierarchies controlling the behaviour of hydras. Nature 199: 1174-1175.

PASSANO, L.M., MCCULLOUGH, C.B. (1964). Co-ordinating systems and behaviour in Hydra. I. Pacemaker system of the periodic contractions. J Exp Bio/41:643-664.

PASSANO, L.M., MCCULLOUGH, C.B. (1965). Co-ordinating systems and behaviour in Hydra II. The rythmic potential system. J Exp Biol 42: 205-231.

POLLINO, C.A., HOLDWAY, D.A. (1999). Potential of two hydra species as standard toxicity test animals. Ecotoxicol Environ Saf 43: 309-316.

RABUS, M., LAFORSCH, C. (2011). Growing large and bulky in the presence of the enemy: Daphnia magna gradually switches the mode of inducible morphological defences. Funct Ecol 25: 1137-1143.

QUINN, B., GAGNE, F., BLAISE, C. (2012). Hydra, a model system for environmental studies. Int J Dev Biol 56: 613-625.

RACHAMIM, T., SHER, D. (2012). What Hydra can teach us about chemical ecology - how a simple, soft organism survives in a hostile aqueous environment. Int J Dev Biol 56: 605-611.

RATCLIFF, M. (2012). The Trembley Effect or the birth of marine zoology. Int J Dev Biol 56: 425-436.

SANTILLO, S., ORLANDO, P., DE PETROCELLIS, L., CRISTINO, L., GUGLIELMOTTI, V., MUSIO, C. (2006). Evolving visual pigments: hints from the opsin-based proteins in a phylogenetically old "eyeless" invertebrate. Biosystems 86: 3-17.

SCHULZE, P. (1917). Neue Beiträge zu einer Monographie der Gattung Hydra. Arch Biontol 4: 29-119.

SCHULZE, P. (1927). Zur Kenntnis und geographischen Verbreitung der Süsswasserpolypen. Zool Anz 74: 129-140.

SCHWARTZ, S.S., HERBERT, P.D.N. (1989). The effect of Hydra on the outcome of competition between Daphnia and Simocephalus. Biol Bull 176: 147-154.

SEMAL-VAN GANSEN, P. (1954). La structure des nématocystes de l'Hydre d'eau douce. Bull Acad Roy Belgique, Cl Sci 40: 269-287.

SHER, D., FISHMAN, Y., ZHANG, M., LEBENDIKER, M., GAATHON, A., MANCHENO, J.M., ZLOTKIN, E. (2005). Hydralysins, a new category of beta-pore-forming toxins in cnidaria. J Biol Chem 280: 22847-22855.

SHER, D., ZLOTKIN, E. (2009). A hydra with many heads: protein and polypeptide toxins from hydra and their biological roles. Toxicon 54: 1148-1161.

SHIMIZU, H. (2012). Transplantation analysis of developmental mechanisms in Hydra. Int J Dev Biol 56: 463-472.

SLOBODKIN, L.B., BOSSERT, P. (1991). The freshwater Cnidaria-or coelenterates. In Ecology and classification of North American freshwater invertebrates. (THORP, J.H., COVICH, A.P. Eds.). Academic Press, San Diego, Caifornia USA, pp. 125-142.

SLOBODKIN, L.B., BOSSERT, P. (2009). The freshwater Cnidaria or coelenterates. In Ecology and Classification of North American Freshwater Invertebrates. (THORP, J.H., COVICH, A.P. Eds.). Academic Press, San Diego, pp. 125-142.

SPEMANN, H., MANGOLD, H. (1924). Über die Induktion von Embryonalanlagen durch Implantation artfremder Organisatoren. Wilhem Roux's Arch Entw Mech 100: 599-638.

STEBBING, A.R.D., POMROY, A.J. (1979). A sub-lethal technique for assessing the effects of contaminants using Hydra littoralis. Water Res 12: 631-635.

STEELE, R.E. (2002). Developmental signaling in Hydra: what does it take to build a "simple" animal? Dev Biol 248: 199-219.

STEELE, R.E. (2012). The Hydra genome: insights, puzzles, and opportunities for developmental biologists. Int J Dev Biol 56: 535-542.

SUGIYAMA, T., FUJISAWA, T. (1977). Genetic analysis of developmental mechanisms 
in Hydra. III. Characterization of a regeneration deficient strain. J Embryol Exp Morphol 42: 65-77.

TADDEI-FERRETTI, C., CHILLEMI, S., COTUGNO, A. (1987). Modulation of Hydra attenuata rhythmic activity. IV. The mechanism responsible for rhythmic activity. Exp Biol 46: 133-140.
TADDEI-FERRETTI, C., MUSIO, C. (2000). Photobehaviour of Hydra (Cnidaria, Hydrozoa) and correlated mechanisms: a case of extraocular photosensitivity. $J$ Photochem Photobiol B 55: 88-101.

TREMBLEY, A. (1744). Mémoires pour servir à l'histoire d'un genre de polypes d'eau douce, à bras en forme de cornes. Jean \& Herman Verbeek, Leiden. 


\section{Further Related Reading, published previously in the Int. J. Dev. Biol.}

A non-enzymatic microsurgical dissection technique of mouse embryonic tissues for gene expression profiling applications Li Sun, May-Yin Lee and Jacqueline M. Veltmaat Int. J. Dev. Biol. (doi: 10.1387/ijdb.113424ls)

A polymorphic, thrombospondin domain-containing lectin is an oocyte marker in Hydractinia: implications for germ cell specification and sex determination

Brahim Mali, R. Cathriona Millane, Günter Plickert, Marcus Frohme and Uri Frank

Int. J. Dev. Biol. (2011) 55: 103-108

An organizing region in metamorphosing hydrozoan planula larvae - stimulation of axis formation in both larval and in adult tissue Melanie Stumpf, Britta Will, Karola Wittig, Jennifer Kasper, Benjamin Fischer, Jürgen Schmich, Stefanie Seipp and Thomas Leitz Int. J. Dev. Biol. (2010) 54: 795-802

The teaching of Developmental Biology in Spain: future challenges Manuel Marí-Beffa Int. J. Dev. Biol. (2009) 53: 1245-1252

Teaching and research on Developmental Biology in Portugal Sólveig Thorsteinsdóttir, Gabriela Rodrigues and Eduardo G. Crespo Int. J. Dev. Biol. (2009) 53: 1235-1243

Frontiers in fluorescence microscopy

José Rino, José Braga, Ricardo Henriques and Maria Carmo-Fonseca Int. J. Dev. Biol. (2009) 53: 1569-1579

Glycobiology of fertilization in the pig

Edda Töpfer-Petersen, Mahnaz Ekhlasi-Hundrieser and Miroslava Tsolova Int. J. Dev. Biol. (2008) 52: 717-736

Reassessing the role of protein-carbohydrate complementarity during sperm-egg interactions in the mouse

Barry D. Shur

Int. J. Dev. Biol. (2008) 52: 703-715

The structure of sulfated polysaccharides ensures a carbohydrate-based mechanism for species recognition during sea urchin fertilization

Ana-Cristina E.S. Vilela-Silva, Noritaka Hirohashi and Paulo A.S. Mourão

Int. J. Dev. Biol. (2008) 52: 551-559

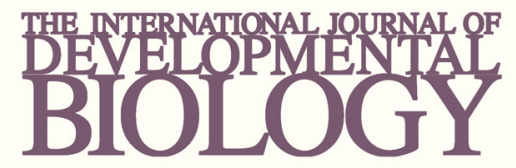

Volume 54 Nos. $6 / 7$
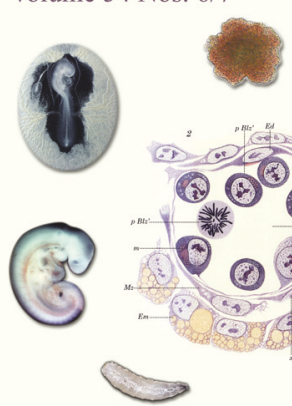

(3) (1)
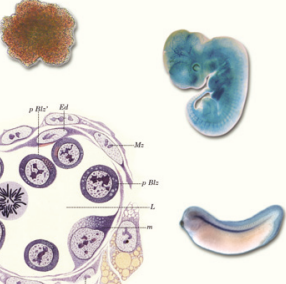

Developmental Hematopoiesis

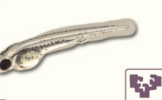

5 yr ISI Impact Factor $(2010)=2.961$

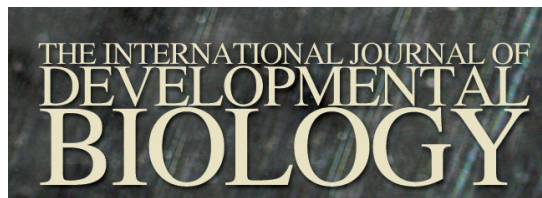

Volume 56

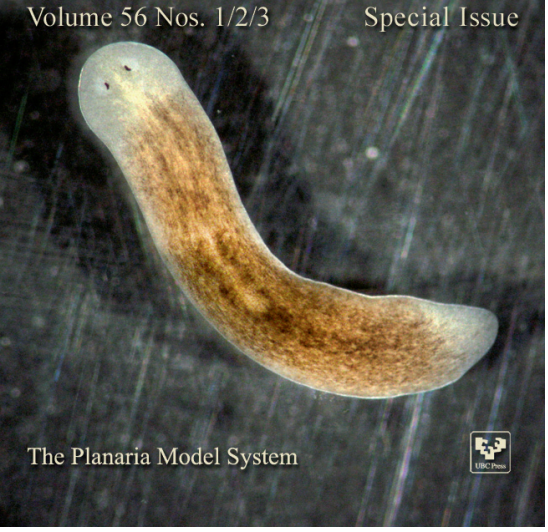

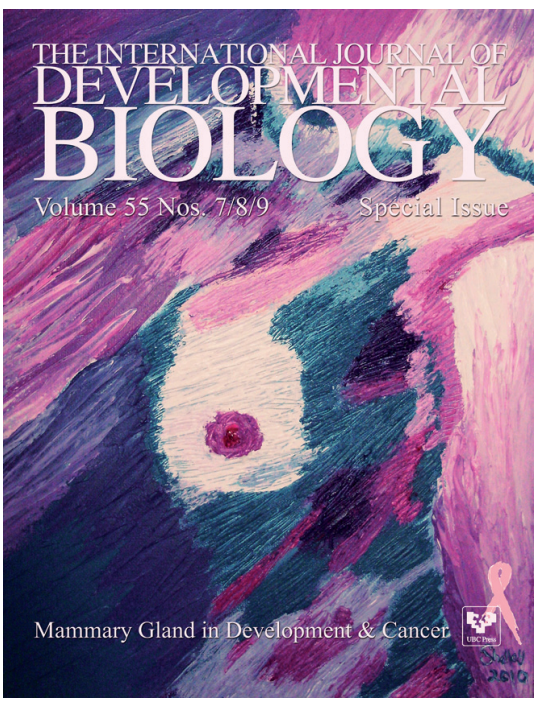

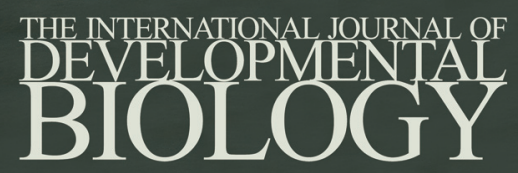

Volume 55 Nos. $4 / 5$

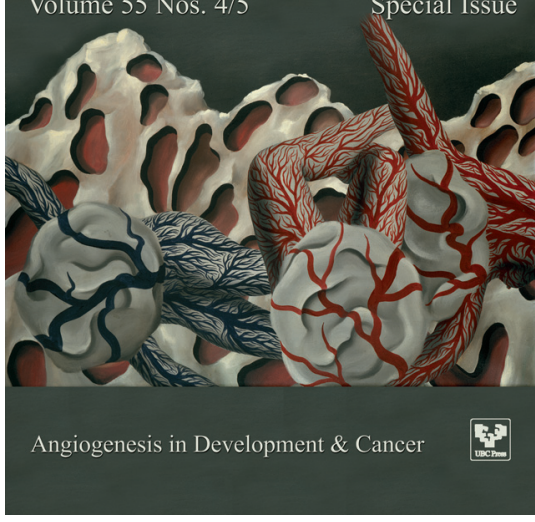

